\title{
Recruitment of predators and parasitoids by herbivore-injured plants
}

\author{
Ted C. J. Turlings \\ Institute of Zoology, University of Neuchatel, Switzerland \\ Felix Wäckers \\ Netherlands Institute of Ecology, Heteren, the Netherlands
}

\section{Introduction}

In recent years, induced plant defenses have received widespread attention from biologists in a variety of disciplines. The mechanisms underlying these defenses and the interactions that mediate them appeal not only to plant physiologists, ecologists, and evolutionary biologists but also to those scientists that search for novel strategies in plant protection. Several recent books (Karban and Baldwin, 1997; Agrawal et al., 1999) and reviews (Baldwin, 1994; Karban et al., 1997; Agrawal and Rutter, 1998; Agrawal and Karban, 1999; Baldwin and Preston, 1999; Dicke et al., 2003) have been devoted entirely to the subject of induced plant defenses. Various forces, ranging from abiotic stresses to biotic factors such as pathogens, arthropods, or higher organisms, may trigger different plant defense responses. Yet, the biochemical pathways that are involved appear to show considerable similarities. This is also true for the so-called indirect defenses.

The term indirect defense refers to those adaptations that result in the recruitment and sustenance of organisms that protect the plants against herbivorous attackers. The early published examples of indirect defenses involved intimate plant-ant interactions, in which myrmecophilous plants were shown to have evolved a range of adaptations providing ants with shelter (domatia) and various food sources (Belt, 1874; Janzen, 1966). In return, these plants may obtain a range of benefits because ants can provide nutrition (Thomson, 1981) or more commonly, protection against herbivores, pathogens, and competing plants (e.g. Koptur, 1992; Oliveira, 1997). The well-documented fitness benefits of ant attendance in myrmecophilous plants (Rico-Gray and Thien, 1989; Oliveira, 1997), combined with the fact that domatia and food supplements are difficult to reconcile with other functions, are convincing arguments for the interpretation that these adaptations represent examples 


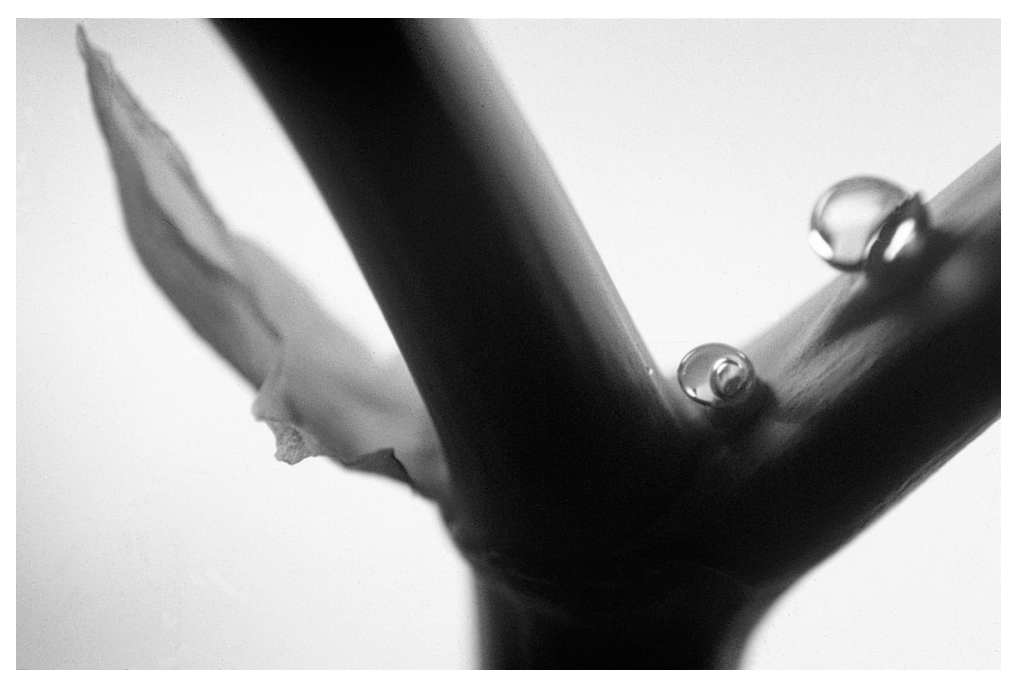

Fig. 2.1. Extrafloral nectar droplets on Ricinus communis (castor bean).

of indirect defense. The above-mentioned studies have all focussed on intimate examples of plant-ant mutualisms. However, similar adaptations are also found in non-myrmecophilous plants. Acarodomatia have been recorded from so-called "mite plants." These preexisting structures facilitate symbiotic interactions with predatory or fungivorous mites (Bakker and Klein, 1992; Whitman, 1994).

Extrafloral nectaries (Fig. 2.1) are probably the most frequently described adaptations believed to serve as indirect defenses. They have been described in approximately 1000 species from 93 plant families including numerous dicotyledonous species, ferns, and such diverse monocotyledonous taxa as lilies, orchids, sedges, and grasses (Koptur, 1992). They are found in virtually all plant types including herbs, vines, shrubs and trees, annuals as well as perennials, and successional as well as climax species.

Often extrafloral nectaries show prominent colorations (primarily black and red), which set them off against the (green) background. In contrast to their floral counterparts, extrafloral nectaries are generally exposed (Zimmerman, 1932), giving insects easy access to the nectar. The nectaries are often situated on leaves or petioles (Fig. 2.1), where they are ideally situated for crawling insects or flying insects that land on the leaf surface (Fig. 2.2). In other plants, they are found on petioles or the (leaf) stem, which is an effective placement for ants and other natural enemies crawling up the plant.

Less evident is the primary function of plant odor emissions. Although it is clear that plant odors are used by parasitoids (Fig. 2.3) and predators to locate potential prey (Vinson et al., 1987; Nordlund et al., 1988; Whitman, 1988), they are likely to have other functions as well (Harrewijn et al., 1995; Turlings and Benrey, 1998). 


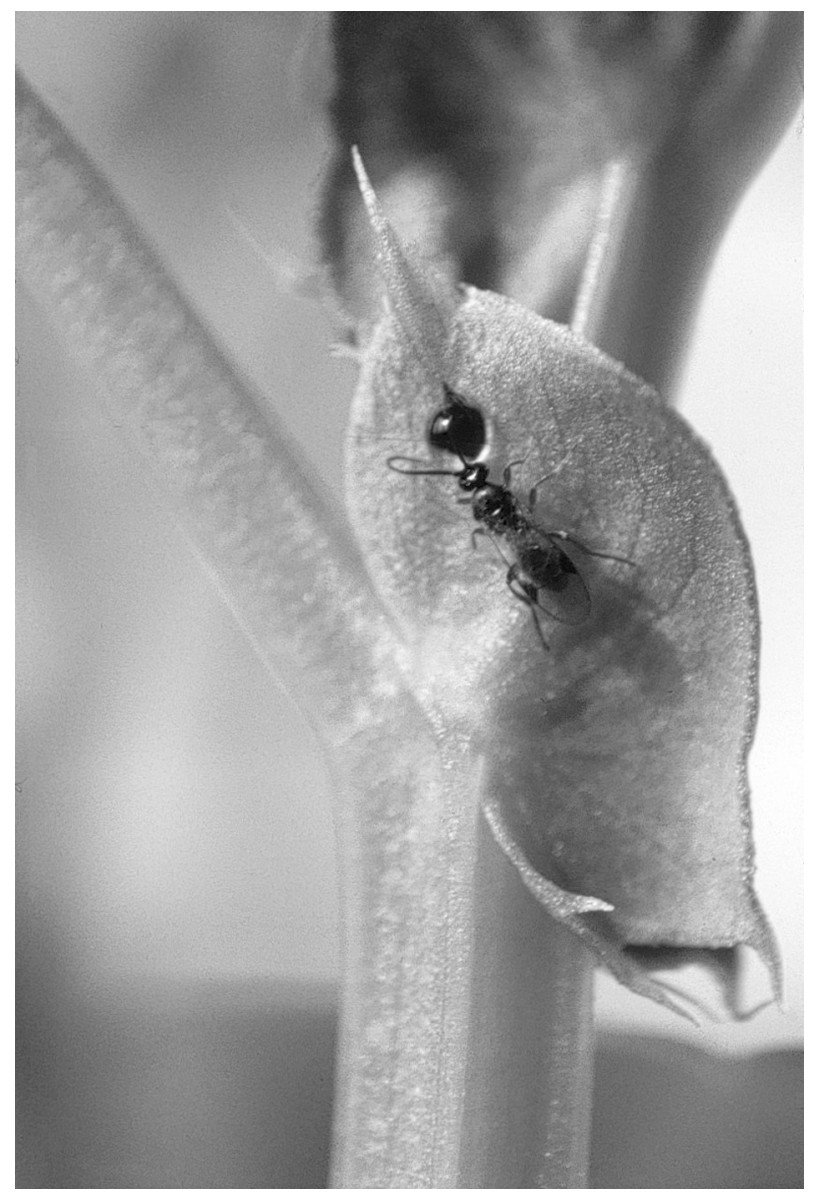

Fig. 2.2. A female of the parasitoid Cotesia glomerata feeding on extrafloral nectar of Vicia faba.

Yet, the notion that plant volatiles may serve as signals to recruit members of the third trophic level has been reinforced by the fact that they are inducible. So far, evidence for plant-produced signals has been limited to interactions between plants and arthropods, but a recent study showed that plants may also recruit nematodes that can infect beetle larvae feeding on the roots of these plants (van Tol et al., 2001). The accumulating evidence strongly suggests that herbivore-induced plant signals play a very important role in the indirect protection of plants against herbivory.

The increasing number of studies on the interactions between plants and the natural enemies of herbivores attacking these plants is revealing an astonishing sophistication. This is most apparent in the specificity of the interactions; plants may respond differently to different herbivores and the natural enemies are able to distinguish among these differences (Sabelis and van de Baan, 1983; Takabayashi et al., 


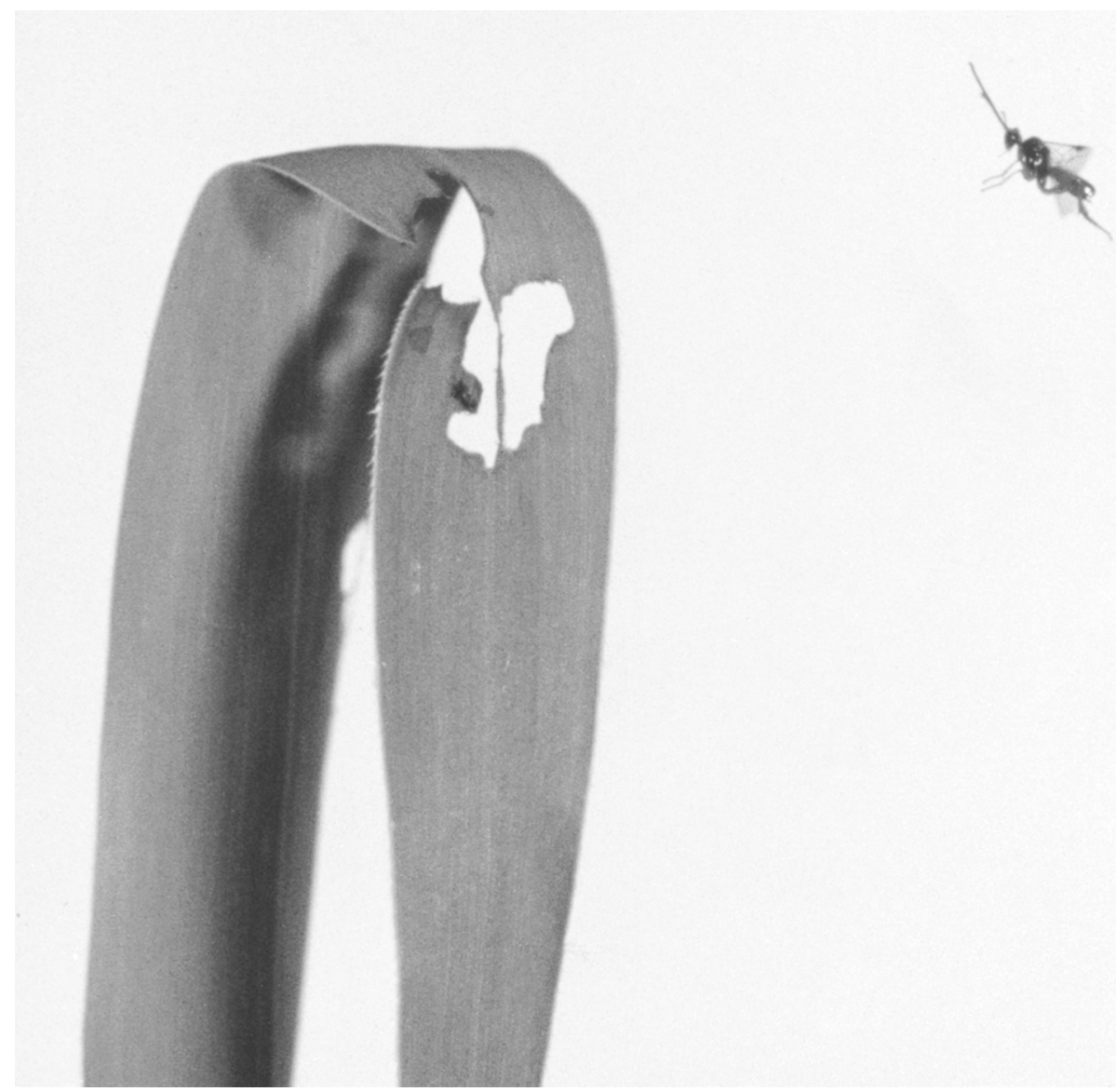

Fig. 2.3. A female of the parasitoid Cotesia marginiventris attracted to the odor emitted by a maize leaf that has been damaged by a Spodoptera exigua larva.

1995; Powell et al., 1998; De Moraes et al., 1998). There is even evidence to suggest that plants selectively employ direct and indirect defenses depending on which herbivore feeds on them (Kahl et al., 2000). An additional twist to the refinement of the interactions is that there is now clear evidence for information transfer among plants mediated by volatile signals (Arimura, et al., 2000a; Dolch and Tscharntke, 2000; Karban et al., 2000). These potent plant signals can be expected to affect multiple interactions within entire food webs (Janssen et al., 1998; Sabelis et al., 1999) and many more interchanges are likely to be discovered.

This chapter gives an overview of the developments in research on induced indirect defenses. We discuss both the ecological aspects as well as our knowledge of the mechanisms that are involved. This chapter differs from most other reviews in that it includes both attraction by means of induced volatiles and the plant's 
strategy to keep the natural enemies of the predator on the plant by increased nectar production in response to herbivory. We compare these two strategies, particularly in terms of timing and specificity of induction. We argue that there is a danger of overinterpreting results if we do not always recognize the fact that plants need to benefit from the proposed function of the induced responses. Hence, our discussion of how natural selection may have shaped the various interactions emphasizes the role of the plant and to what extent its interests are in tune with those of the third trophic level. Some recent studies provide evidence for the adaptiveness of inducible indirect defenses, but it is concluded that field experiments, preferentially with natural systems, are needed to establish truly if plants do benefit from these inducible responses. Field data are also still lacking for a conclusive appreciation of the full potential of exploiting indirect plant defenses in the protection of crop plants.

\section{Inducible volatile signals}

\section{The role of plant volatiles as prey and host location cues}

The evolutionary "cat-and-mouse game" between entomophagous insects and their prey has led to various refined adaptations on both sides. Potential prey may minimize the encounter rates with their natural enemies by being cryptic, visually as well as chemically. Although various natural enemies make use of prey-derived cues (for review see Tumlinson et al., 1992), others have evolved to rely primarily on indirect cues that may be less efficient but are more readily available and detectable (Vet et al., 1991; Vet and Dicke, 1992). For the many natural enemies of herbivores, the plants on which the herbivores feed play a key role in providing useful cues.

That predators and especially parasitoids of herbivores are attracted to plants has long been known. In their review of this topic, Nordlund et al. (1988) suggest that Picard and Rabaud (1914) were the first to realize the importance of plants for foraging entomophagous insects. In numerous studies since (e.g., Taylor, 1932; Zwölfer and Kraus, 1957; Salt, 1958; Harrington and Barbosa, 1978), predators and parasitoids were found more on one plant species than another. That plant volatiles may be responsible for such differential attractiveness was apparent from studies by, among others, Monteith (1955), Arthur (1962), Flint et al. (1979), and Elzen et al. (1984). These studies considered the importance of the plant only at the level of habitat locations, as defined by Vinson (1981). It was not until papers by Price et al. (1980), Vinson (1981), and Barbosa and Saunders (1985) that the more direct role of plants in mediating the step of host/prey location was considered. Initial studies suggested only that insect-derived attractants (kairomones) were affected by the plant diet of the host or prey (e.g., Roth et al., 1978; Sauls et al., 1979; 
Loke et al., 1983). For instance, parasitoid females tend to respond more strongly to feces from host larvae that have fed on their customary host plant than to feces from larvae fed on an artificial diet (Roth et al., 1978; Sauls et al., 1979; Mohyuddin et al., 1981; Nordlund and Sauls, 1981).

The first series of studies to provide complete behavioral as well as chemical evidence for the ability of herbivore-injured plants actively to attract natural enemies of their predators was obtained with studies on plant-mite interactions (e.g., Sabelis and van de Baan, 1983; Dicke and Sabelis, 1988; Dicke et al., 1990a,b). First, it was found that plants infested with spider mites were far more attractive to predators than were uninfested plants (Sabelis and van de Baan, 1983). Subsequently, Dicke and Sabelis (1988) showed the presence of several unique volatile substances in the headspace collections of lima bean leaves infested with the spider mite Tetranychus urticae. These volatiles were not emitted by the spider mites but by the infested plant. Synthetic versions of some of these substances, which were not present in the collections from uninfested plants, were attractive to the predatory mite Phytoseiulus persimilis. These first studies and many since (e.g., Dicke et al., 1990a,b; Takabayashi et al., 1991a, 1994; Scutareanu et al., 1997) show that P. persimilis and various other predators that use phytophagous mites as prey make effective use of a specific blend of mite-induced compounds to locate plants with prey. This well-studied model system has proven very valuable in revealing the intricacies and complexity of a multitude of interactions that can be affected by the herbivore-induced plant volatiles (Janssen et al., 1998; Sabelis et al., 1999).

The majority of other studies that show conclusively that herbivory induces plants to emit volatiles that may serve as an indirect defense involving the attraction of parasitoids (Table 2.1). In particular, studies with caterpillars on cotton (McCall et al., 1993, 1994; Loughrin et al., 1994, 1995a; Röse et al., 1996), Brassica spp. (Steinberg et al., 1992; Agelopoulos and Keller, 1994; Mattiacci et al., 1994; Geervliet et al., 1994; Benrey et al., 1997), and maize (Turlings et al., 1990, 1991a,b, 1995; Takabayashi et al., 1995; Potting et al., 1995; Alborn et al., 1997) have revealed that caterpillar damage results in the release of parasitoid attractants. In most cases, injury by caterpillars was found to cause a much stronger reaction in terms of odor emissions than mechanical damage. Relatively new is the finding that egg deposition by herbivores on plants can cause plants to release volatiles that are attractive to egg parasitoids (Meiners and Hilker, 1997, 2000; Meiners et al., 2000). The plant response to egg deposition also appears to be systemic (Wegener et al., 2001).

Many additional studies show that herbivore-induced emissions of volatiles are very common and are found in a wide range of plant taxa, induced by numerous herbivorous arthropods, and affect many different natural enemies (Table 2.1). The list in Table 2.1 is not meant to be complete but rather to illustrate how common these 


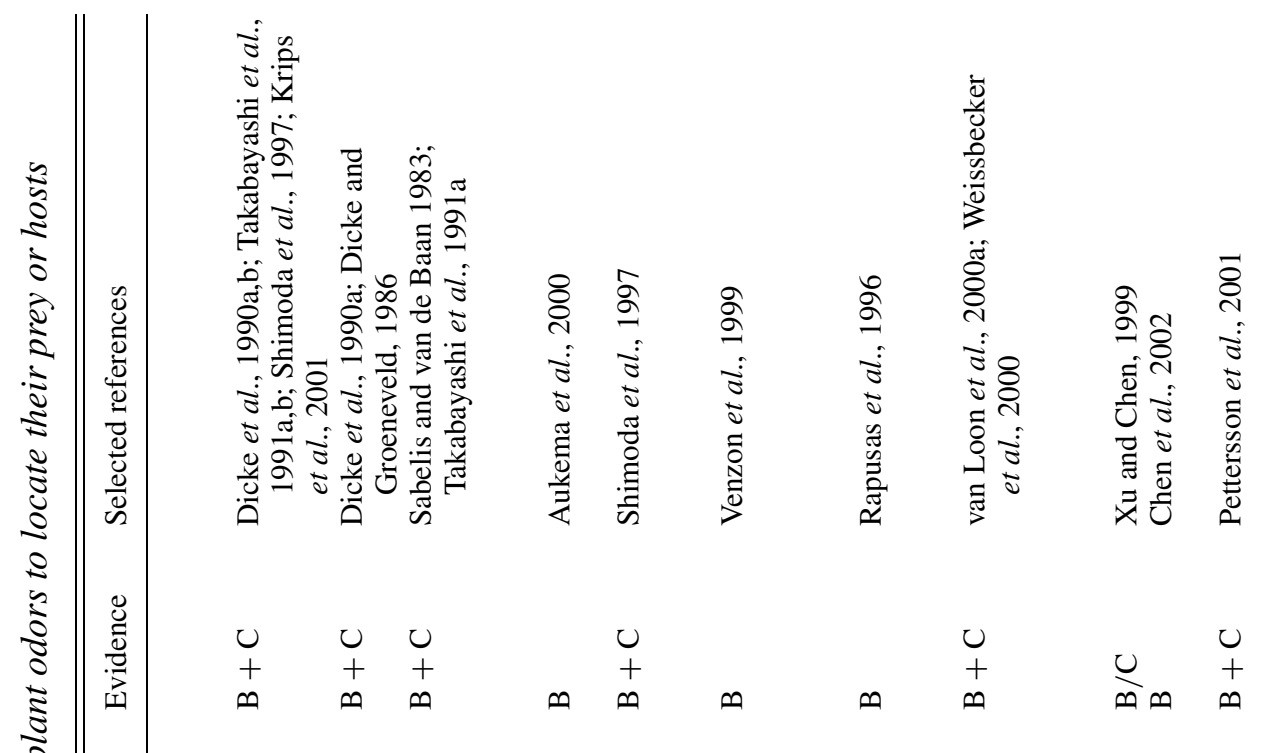

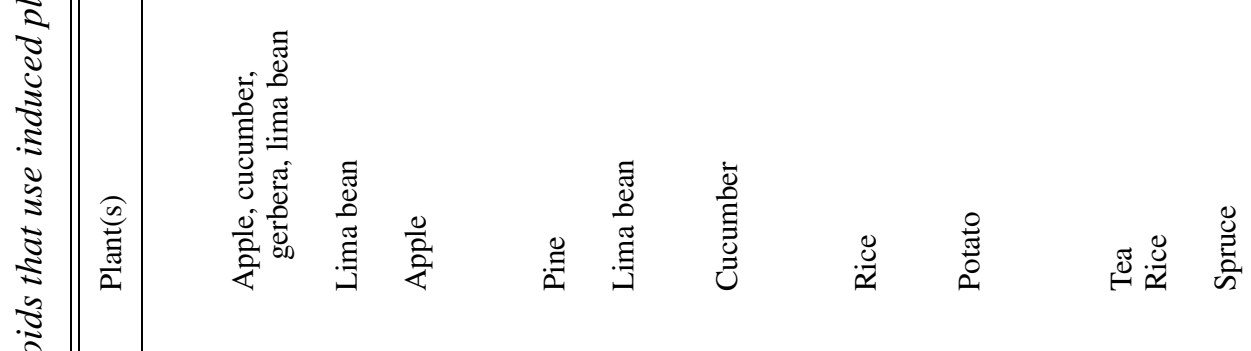

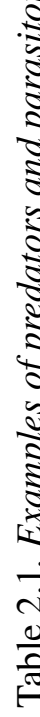

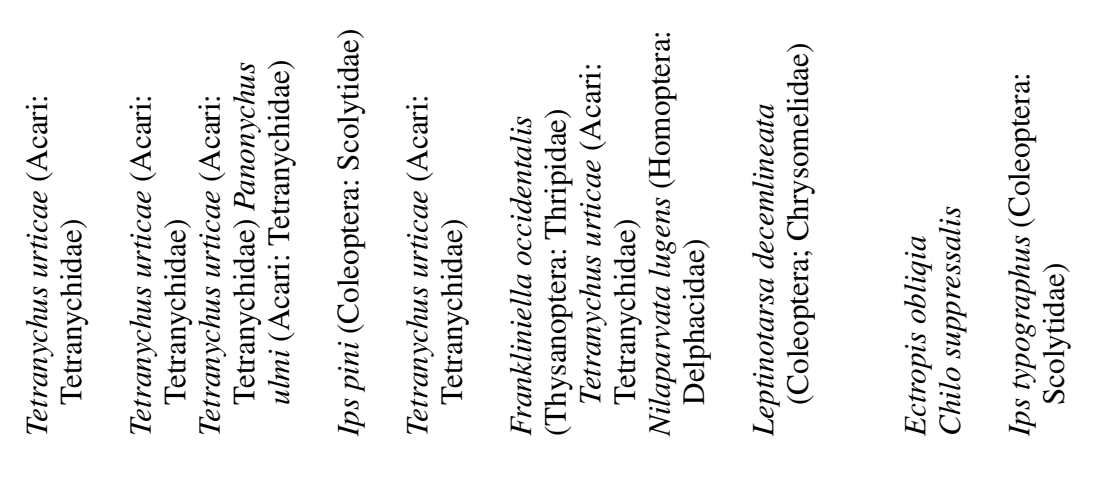




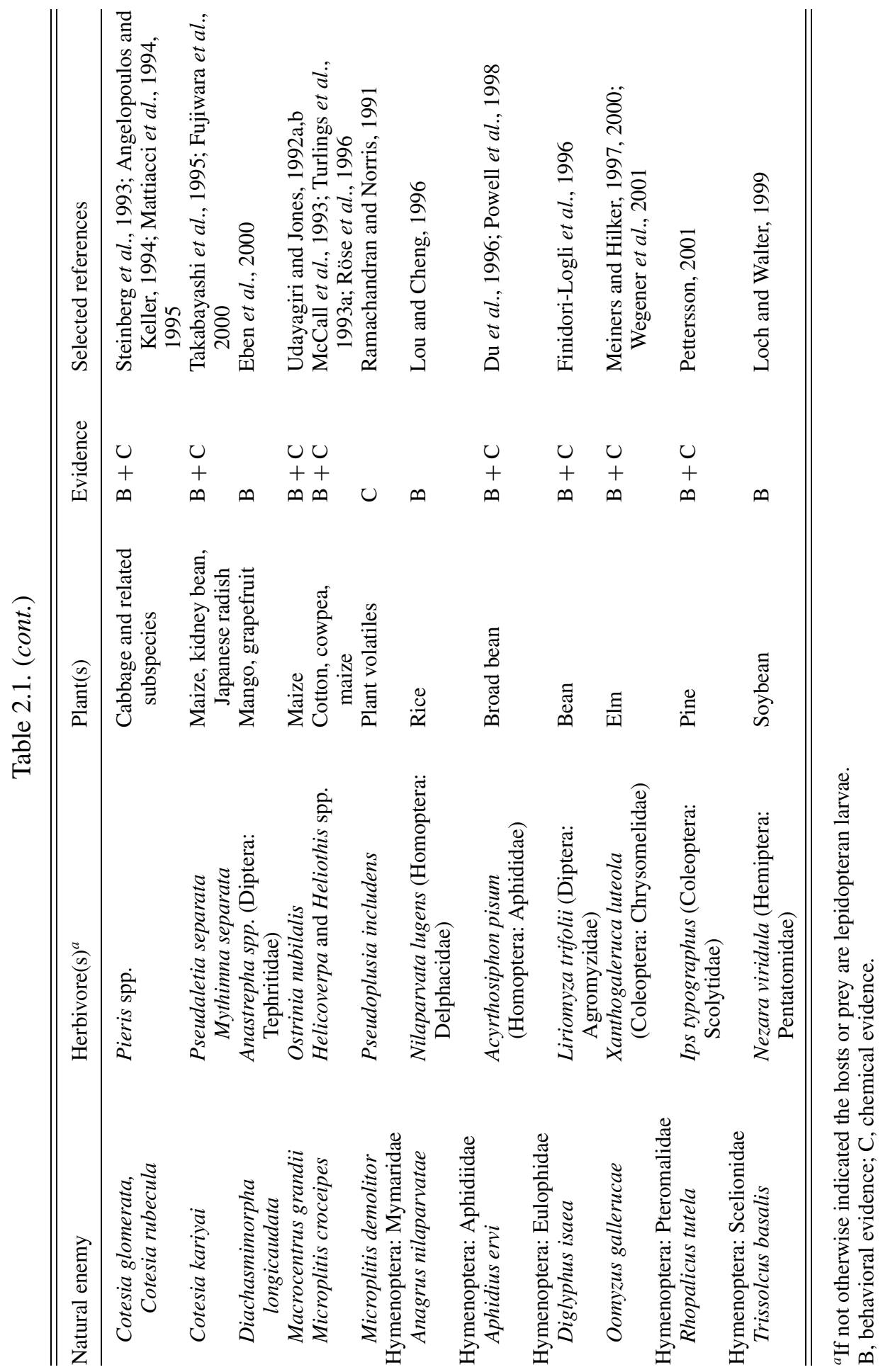


tritrophic interactions are. The evidence is not equally conclusive in all cases, but behavioral observations and/or chemical analyses strongly indicate that induced plant volatiles play a key role in host or prey location. Current research in this area focusses on the mechanisms of induction and on questions concerning the ecological significance and evolutionary history of these interactions, as well as on the possibility of exploiting this indirect plant defense for crop protection. We attempt to give an overview of the most significant findings of these research efforts.

\section{Elicitors and induction mechanisms}

Mere mechanical damage of leaves may result in the temporary emission of some volatiles, but in most cases these emissions can be greatly enhanced and prolonged by eliciting factors that come directly from a feeding insect. These factors also elicit odor emissions when undamaged leaves take them up via the petiole, and the response to these factors has been shown to be systemic (Dicke et al., 1990a; Turlings et al., 1993a). After the isolation and identification of a $\beta$-glucosidase (Mattiacci et al., 1995) and the fatty acid derivative volicitin (Alborn et al., 1997) as elicitors from caterpillar oral secretion (regurgitant), a multitude of studies have revealed details about the mechanisms that may mediate the formation and action of these compounds. Notably the groups of Tumlinson (Gainesville, Florida) and Boland (Jena, Germany) have made considerable progress in these areas, as summarized below.

\section{Beta-glucosidase}

A $\beta$-glucosidase in the regurgitant of Pieris brassicae larvae causes a release of volatiles in brassica plants that is similar to the release observed after feeding by these larvae (Mattiaci et al., 1995). Beta-glucosidases are present in many organisms (e.g., Robinson et al., 1967; Sano et al., 1975; Wertz and Downing, 1989; $\mathrm{Yu}, 1989$ ) and may function in catalyzing biochemical pathways that involve glycoside cleavage. The emissions by Brassicaceae are characterized by glucosinolate breakdown products, which have not been observed in other plant families that have been studied in this context (Agelopoulos and Keller, 1994; Mattiaci et al., 1994; Geervliet et al., 1996). It is expected that enzymes like $\beta$-glucosidase facilitate this glucosinolate breakdown. This notion is reinforced by the fact that a systemic emission after caterpillar feeding is only observed if the distant leaves are mechanically damaged (L. Mattiaci, personal communication), suggesting that the substrate comes in contact with enzymes only when it is released from ruptured cells. The key enzyme involved in the hydrolysis of glucosinolates is myrosinase, which causes the release of volatile defensive compounds such as isothiocyanates (Bones and Rossiter, 1996). The bioactivity of enzymes in the oral secretions of insects as inducers of volatile emissions may be limited to specific plant taxa. 


\section{Volicitin}

Incubation of young maize plants in the regurgitant of several lepidopteran larvae and a grasshopper was found to induce the release of a blend of terpenoids and indole that is typical for plants with caterpillar damage (Turlings et al., 1993a). Similarly, Potting et al. (1995) found that stemborer regurgitant applied to mechanically damaged sites caused an increase in induced odor emissions in maize plants. In both cases, induced plants were more attractive to parasitoids than plants that were not induced.

Volicitin ( $N$-(17-hydroxylinolenoyl)-L-glutamine) was identified by Alborn et al. (1997) as the active substance in the regurgitant of Spodoptera exigua larvae. Low concentrations of this elicitor alone cause the same reaction in maize plants as pure regurgitant and render the plants equally attractive to the parasitoids (Turlings et al., 2000). So far, volicitin has only been shown to be active in maize (Turlings et al., 2002) and does not induce a reaction in, for instance, lima bean (Koch et al., 1999). Studies of the source and biosynthesis of volicitin revealed that this fatty acid derivative is formed in the bucal cavity of the insect (Paré et al., 1998). Linolenic acid, the fatty acid part of volicitin, is ingested with plant material and is then 17-hydroxylated and conjugated with insect-derived glutamine (Paré et al., 1998). Spiteller et al. (2000) showed that bacteria isolated from caterpillar gut contents are able to synthesize volicitin and other $N$-acylglutamine conjugates from externally added precursors. Hence, it is not necessarily the plant or the insect that controls the biosynthesis of volicitin. It remains surprising, however, that the insects "allow" the synthesis of elicitors that trigger plant reactions with such negative consequences for the insect. It is, therefore, expected that these metabolites play an essential role in the insects' physiology. Perhaps they serve as surfactants that facilitate the transport and digestion of food, or they may neutralize the effects of plant toxins (Alborn et al., 2000; Spiteller et al., 2000). Numerous $N$-acylglutamates that may show elicitor activity (Halitschke et al., 2001) occur in the oral secretions of various insects (Pohnert et al., 1999; Spiteller et al., 2000).

Not surprisingly, some factors in the oral secretions of caterpillars may suppress induced plant defenses (Felton and Eichenseer, 2000). Musser et al. (2002) elegantly showed that the enzyme glucose oxidase in the saliva of Helicoverpa zea counteracts the induced production of nicotine. The presence of such suppressing agents would explain the fact that the isolated active fraction containing volicitin showed more activity than pure caterpillar regurgitant (Turlings et al., 2000).

\section{Elicitors from plants}

Plant hormones with various functions have been identified over the years and an increasing number of studies show that they may also affect volatile emissions 
(Farmer, 2001). Even nectar production may be effected by such hormones (Heil et al., 2001). The gaseous hormone ethylene plays an important role in plant development, but also in defense (Mattoo and Suttle, 1991). Upon perception of a pathogen, plants show enhanced ethylene production, which has been shown to be involved in the induction of defense reactions (Boller, 1991). Wild tobacco plants engineered with an Arabidopsis sp. ethylene-insensitive gene do not show typical leaf development arrestment in the presence of leaves of other tobacco plants, demonstrating the importance of ethylene in plant development (Knoester et al., 1998). The ethylene-insensitive plants also showed reduced defense protein synthesis and were susceptible to soil pathogens to which they were normally fully resistant. In connection with the third trophic level, Kahl et al. (2000) found that attack by Manduca caterpillars on wild tobacco plants causes an ethylene burst that suppressed induced nicotine production but stimulated volatile emissions. They argued that the plant "chooses" to employ an indirect defense (the attraction of natural enemies) rather than a direct defense to which the attacker could adapt (Kahl et al., 2000; Winz and Baldwin, 2001). This implies that the plant is capable of identifying its attacker. We discuss this possibility in more detail in the discussion of specificity.

Studies into the effects and mechanisms of induced resistance against pathogens and insects have revealed the role of salicylic acid (SA) and jasmonic acid (JA). These compounds are seen as the key signals for defense gene expression (Reymond and Farmer, 1998). It was generally thought that SA regulates resistance to fungal, bacterial, and viral pathogens (Enyedi et al., 1992; Ryals et al., 1996), whereas $\mathrm{JA}$ induces the production of various proteins via the octadecanoid pathway that provides plants with resistance against insects (Broadway et al., 1986; Farmer et al., 1992). However, this distinction between the two pathways is not that clear and pathogens and arthropods may sometimes trigger both (Farmer et al., 1998; Reymond and Farmer, 1998; Walling, 2000). SA and JA, as well as synthetic mimics, can be applied exogenously to plants to induce the same metabolic changes that lead to resistance as induced by pathogens and insects (Ryals et al., 1992; Kessmann et al., 1994; Görlach et al., 1996; Thaler et al., 1996). The two different pathways that the elicitors stimulate can compromise each other (Doherty et al., 1988). Thaler (1999) demonstrated this in a field situation, where tomato plants stimulated with a SA mimic reduced resistance to S. exigua, while JA treatment rendered plants more vulnerable to the bacterial speck pathogen Pseudomonas syringae pv. tomato.

Treatment with SA, JA, or their mimics can also induce the release of volatiles in plants, but the blends produced are somewhat different for the two elicitors (Hopke et al., 1994; Dicke et al., 1993, 1999; Ozawa et al., 2000; Wegener et al., 2001; Rodriguez-Saona et al., 2001). In a rare field experiment (see below), Thaler (1999) showed that treatment of tomato plants with JA increased the parasitism rate of 
caterpillars on the plants, which was most likely the result of JA-induced increases in odor emissions. The overall evidence clearly indicates that these inducers of general defense reactions also play a role in volatile signaling.

Arimura et al. (2000a) found that several of the induced volatiles themselves can serve as elicitors by triggering gene activation in neighboring leaves that leads to further emissions. In this context, $(Z)$-jasmone was shown to be a potent plantderived volatile elicitor that triggers the release of $(E)$ - $\beta$-ocimene in the bean plant, Vicia faba (Birkett et al., 2000). These examples of plant odours inducing plant defense pathways have important implications for plant-plant communication (see below).

\section{Pathogen-derived elicitors}

Cellulysin is a fungus-derived enzyme mixture of exo- and endoglucanases that is an extremely potent elicitor of plant volatile biosynthesis through the upregulation of the octadecanoid pathway (Piel et al., 1997). The low-molecular-weight phytotoxin coronatin, which is produced by certain bacteria (Bender et al., 1996; Ichihara et al., 1977), is also a strong elicitor of volatile emissions and mimics specific compounds within the pathway (Weiler et al., 1994; Boland et al., 1995; Schüler et al., 2001). More recently, a mixture containing the ion channel-forming peptide of the peptaibol class (alamethicin), isolated from the plant parasitic fungus Tricoderma viride, has also been implicated in volatile induction via the octadecanoid-signaling pathway (Engelberth et al., 2000, 2001). It should be noted that the induced volatile blends show considerable differences for the different elicitors. In lima bean, alamethicin only induces the production of the two common homoterpenes (3E)-4,8-dimethyl-1,3,7-nonatriene (DMNT) and (3E,7E)-4,8, 12-trimethyl-1,3,7,11-tridecatetraene (TMTT), and of methyl salicilate. These compounds are barely induced after treatment with JA or cellulysin, which stimulate the production of other inducible volatiles (Engelberth et al., 2001). Coronatin and its synthetic mimic coronalon induce the production of a complete blend of all these compounds (Schüler et al., 2001). The common elicitation of volatile synthesis by pathogens is likely to affect insect induction if simultaneous infections occur and should be considered in future studies on variability and specificity of plant-provided signals (see below).

\section{The genetic basis for induction}

Common elicitors like JA and SA and knowledge about the biochemical pathways that they induce are used to identify the plant genes that are involved in the induction process (Reymond et al., 2000). Various genes that are induced by JA and related compounds have been identified (Reymond and Farmer, 1998; Stinzi et al., 2001) and several of these genes can also be activated by some of the induced 
volatiles themselves (Arimura et al., 2000a). However, very little is known about the genes that code for the enzymes involved in the direct synthesis of specific induced volatiles.

One of the main substances induced in maize by volicitin is indole, an intermediate in at least two biosynthetic pathways. Frey et al. (2000) identified a new enzyme, indole-3-glycerol phosphate lyase, which converts indole-3-glycerol phosphate to free indole. They found that the corresponding gene igl is selectively activated by volicitin. This differs from previously known enzymes like BX1, which catalyzes the conversion of indole-3-glycerol phosphate to indole to form the secondary defense compounds DIBOA (2,4-dihydroxy-2H-1,4-benzoxazin-3(4H)one) and DIMBOA (2,4-dihydroxy-7-methoxy-2H-1,4-benzoxazin-3(4H)-one), or tryptophan synthase, which produces the amino acid trytophan (Frey et al., 1997). The selective activation of the evolutionarily similar genes igl and $b x l$ strongly suggests that the plants are capable of selecting which induced defense to use depending on the attacking species.

Volicitin has also been shown to activate a specific maize sesquiterpene cyclase gene, $s t c l$, which is also activated in response to caterpillar feeding or regurgitant treatment (Shen et al., 2000). The transcription of $s t c l$ results in the production of a naphtalene-based sesquiterpenoid, which we have not yet detected from the many maize lines we have studied (e.g., Gouinguené et al., 2001). It would be interesting to see if this volicitin-induced substance shows attractiveness to natural enemies of the caterpillars that induce its production.

One of the terpenoids that is almost always found in induced odor blends of many plants species is the acyclic $\mathrm{C}_{11}$ homoterpene DMNT (Boland et al., 1992; Dicke, 1994). Biosynthesis of DMNT proceeds via (E)-nerolidol, a sesquiterpene alcohol (Boland and Gäbler, 1989; Donath and Boland, 1994; Degenhardt and Gershenzon, 2000). Degenhardt and Gershenzon (2000) demonstrated the activity of a $(E)$-nerolidol synthase that converts farnesyl bisphosphate, a common precursor of sesquiterpenes, to $(3 S)$ - $(E)$-nerolidol in maize leaves after the leaves had been damaged by Spodoptera littoralis larvae. Activity of $(E)$-nerolidol synthase has also been shown in lima bean and cucumber leaves in response to spider mite feeding on these leaves (Bouwmeester et al., 1999). (E)-Nerolidol synthase appears to be specifically committed to the formation of DMNT and could play a key role in determining the attractiveness of herbivore-injured plants to natural enemies (Degenhardt and Gershenzon, 2000).

The apparent selective activation of genes responsible for induced odor production and the committed function of the resulting enzymes may allow for a precise fine tuning between insect-derived elicitors and the responses of the plant. Thus, plants have the potential to adapt their signals specifically to the insect that feeds on a plant. Several studies present evidence for such specificity. 


\section{Specificity}

If plants respond differentially to different herbivores, producing a distinct blend of volatiles in each case, the signals may provide the natural enemies with specific information on the identity and perhaps even stage of the herbivores present on a plant. Evidence for and against such specificity is accumulating. Dicke (1999) has listed various examples that indicate specificity as well as those that suggest a lack of specificity. For instance, Takabayashi et al. (1995) found that only the 1st through the 4th instar larvae of Pseudaletia separata (Lepidoptera: Noctuidae) induced a significant production of volatiles in maize. In accordance, the parasitoid Cotesia kariyi is attracted primarily to maize plants eaten by early instar larvae, which are suitable for parasitization (Takabayashi et al., 1995). However, no such specificity was found for the interaction between maize plants, larvae of S. littoralis (Lepidoptera: Noctuidae), and the parasitoid Microplitis rufiventris, which also attacks only the early stages of this preferred host (Gouinguené, 2000).

Other examples of specificity show that different herbivore species cause different reactions in a plant. These differences can be in the total quantity of volatiles released (Turlings et al., 1998) or in actual differences in the composition of the odor blend (Turlings et al., 1993a; Du et al., 1998; De Moraes et al., 1998). A very distinct difference occurs in the ratios among typical green leaf volatiles released by plants damaged by either Spodoptera frugiperda or S. exigua (Turlings et al., 1993a). Maize damaged by $S$. frugiperda emitted far more (E)-2-hexenal than maize damaged by $S$. exigua. The parasitoid was able to learn to distinguish between the two types of damage (Turlings et al., 1993a), but it remains unclear whether $(E)$-2-hexenal played a role in this. It should be noted that the release of green leaf volatiles in maize does not appear to be enhanced by elicitors; these volatiles "bleed" instantanuously from damaged sites.

Learning is not required for the aphid parasitoid Aphidius ervi to recognize pea plants that are damaged by its specific host, the pea aphid Acyrthosiphon pisum (Du et al., 1998; Powell et al., 1998). This parasitoid is far more attracted by pea plants infested by this host than by pea plants infested by a non-host, Aphis fabae. Implicated in the specificity of the signal is 6-methyl-5-hepten-2-one, a substance that was only detected in the odor profile of plants infested by A. pisum (Wadhams et al., 1999); the pure compound was found to be highly attractive to A. ervi (Du et al., 1998).

Behavioral and chemical evidence for signal specificity was also obtained by De Moraes et al. (1998). They found that Cardiochiles nigriceps, a parasitoid that specializes on Heliothis virescens, is much more attracted to plants attacked by its host than by plants attacked by the closely related non-host $\mathrm{H}$. zea. Volatile collections from maize and tobacco plants that had been subjected to feeding by these 
noctuids showed differences in the relative ratios of some of the major compounds. It remains to be determined whether these observed differences allow $C$. nigriceps to recognize plants with hosts.

Two novel studies (Kahl et al., 2000; De Moraes et al., 2001) have reached some spectacular conclusions concerning specific responses to insect feeding. Kahl et al. (2000) showed that wild tobacco, Nicotiana attenuata, does not increase its production of nicotine after it has been damaged by nicotine-tolerant Manduca sexta caterpillars. Any other form of damage is known to result in the accumulation of nicotine in this plant, through stimulation of the JA signal cascade. It was subsequently confirmed that an ethylene burst resulting from M. sexta feeding suppressed nicotine production (Winz and Baldwin, 2001). The authors suggested that the plant chooses not to use its direct defense against this well-adapted adversary but instead mobilizes a strong indirect defense with the release of considerable amounts of volatiles that were shown to attract natural enemies (Kessler and Baldwin, 2001). They also point out that ingested nicotine probably has not much effect on M. sexta but may negatively affect its natural enemies. Equally interesting is the finding by De Moraes et al. (2001) that in Nicotiana tabacum the odor emitted after caterpillar feeding is different during the night than during the day. The day-time volatiles are known to attract parasitoids (De Moraes et al., 1998), whereas the night time volatiles repelled female $H$. viresens moths and kept them from laying eggs on the emitting plants (De Moraes et al., 2001). Again the plant appears to choose what and when to emit.

These examples suggest great sophistication in how the plants "choose" to respond to herbivore attack. However, the ability of natural enemies to take advantage of this specificity may be hampered by the great variability that can be observed among different genotypes of a plant species in the release of the major volatile compounds. Possibly, subtle differences in some of the minor compounds play an important role in determining signal specificity. Below we discuss this genotypic variation and its implication for the reliability and specificity of herbivore-induced signals.

\section{Variability}

It seems that plant-provided signals are limited in the specific information that they can provide because of the high variability that is found among plant genotypes (Takabayashi et al., 1991b; Loughrin et al., 1995a; Gouinguené et al., 2001, Krips et al., 2001). Variation can also be found between plant parts (Turlings et al., 1993b) and between different growth stages of a plant (Gouinguené, 2000). Moreover, many parasitoids and predators, whether they are generalists or not, can find their hosts or 
prey on a variety of plant species and each of these has its own characteristic basic odor blend. Therefore, natural enemies that use plant odors to locate their prey will need to determine which odors are most reliably associated with a certain prey at a certain time.

The variation in odor emissions that can be found among plant species is illustrated in Fig. 2.4. The chromatograms depict the volatile blends released by four crop plant species (maize, cotton, cowpea, and alfalfa) at different times after an attack by the common lepidopteran pest $S$. littoralis. For this experiment, 2- to 4week-old plants that had been grown in pots in a climate chamber were transplanted into a glass vessel (a cylinder $10 \mathrm{~cm}$ in diameter and $45 \mathrm{~cm}$ high) the day before odor collections started. Pure humidified air was pumped into each vessel just above soil level, while close to the open top of the vessel most of the air was pulled out through a collection trap. With this technique, which is similar to the one described by Turlings et al. (1998), the volatiles emitted by each plant were collected for periods of $3 \mathrm{~h}$. The volatiles were extracted from the traps, two internal standards were added, and each sample was analyzed on a gas chromatograph coupled to a mass spectrometer. The top chromatograms in Fig. 2.4 show the odor emissions before caterpillar attack. Most plants are virtually odorless when undamaged, but some, like the maize line used here, constitutively release a few substances (e.g., linalool and $(E, E)$ - $\alpha$-farnesene).

After the first $3 \mathrm{~h}$ collection, 20 starved 3-day-old $S$. littoralis larvae were placed on each plant. A new $3 \mathrm{~h}$ collection was started immediately after. As can be seen in the second chromatogram for each plant, there was considerable variation in the types of substance that were released by each plant, but all of them released the highly volatile green leaf odors (e.g., (E)-2-hexenal, (Z)-3-hexenol, and (Z)-3hexenyl acetate). These volatiles are characteristic for fresh damage and may play a common role in the initial attraction of nave natural enemies to damaged plants (Fritzsche Hoballah et al., 2002) as well as in the location of recently damaged sites on a plant. Of the plants tested, cotton was the only one that showed an immediate release of significant amounts of several of terpenoids (e.g., $\alpha$-pinene, $\beta$-pinene, and caryophyllene). These terpenoids are stored in glands located near the surface of cotton leaves and are released when the glands are ruptured (Elzen et al., 1985; Loughrin et al., 1994). In maize, only small amounts of induced terpenoids were collected during the first hours of attack. We had previously shown (Turlings et al., 1998) that these are compounds induced after caterpillar damage and that the reaction in this plant can be observed within hours.

That maize is faster in the production of induced substances than the other plants is clear from the remaining chromatograms. On the second day of the experiment, the maize plants showed a full release of all induced substances, while for the other plants the release takes more time. After 2 days, cotton plants also released induced 


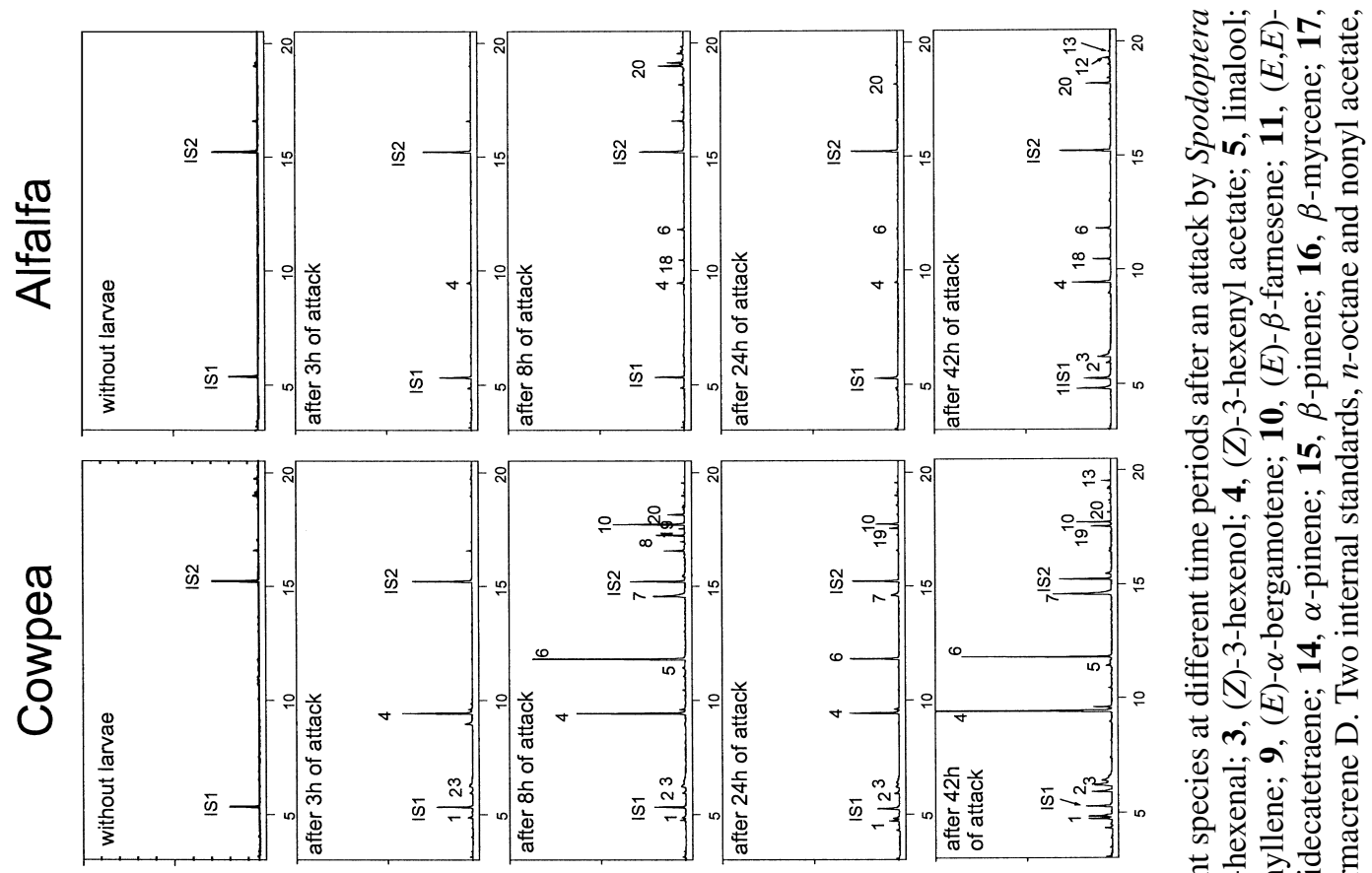

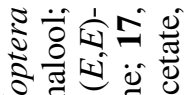
ธิษ 어을 बेष्ठ 후ㅇㅝㅠ

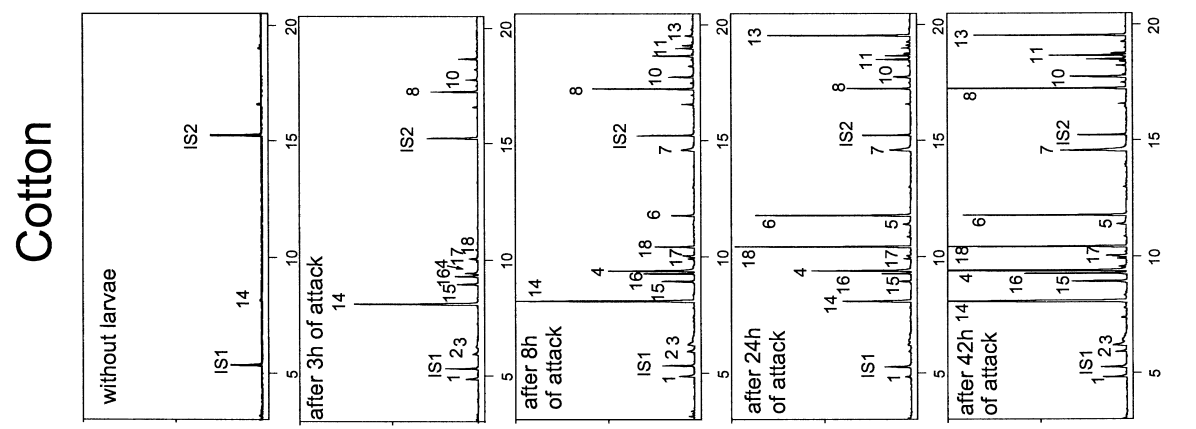

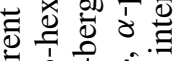
氙 陚团记 त r

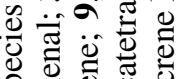

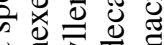

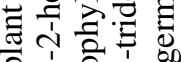

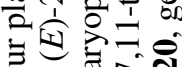
ठำกำ ลำ월

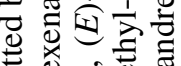

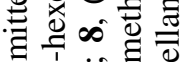

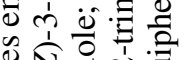
嵌 要 包前成

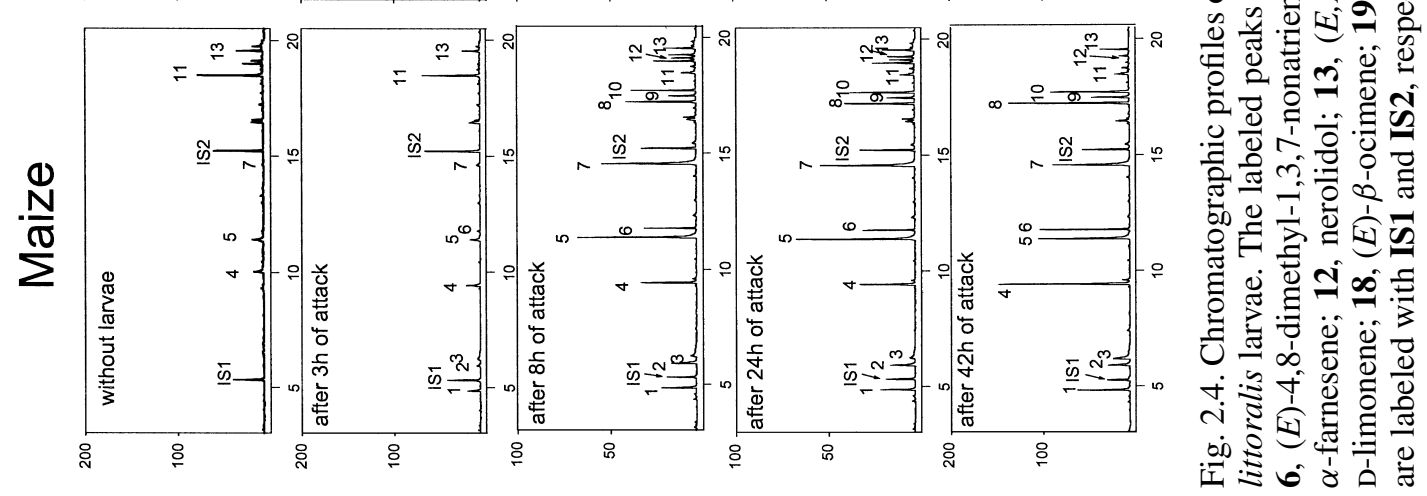


terpenoids (e.g., $(E)$ - $\beta$-ocimene, DMNT, ( $E$ )- $\beta$-farnesene) alongside the ones that are released constitutively from the glands (see also McCall et al., 1993; Loughrin et al., 1994; Röse et al., 1996). The late reaction in this plant may be a strategy in which it first relies on its stored defenses and then, when an attack continues, switches to an induced defense.

The cowpea and especially alfalfa plants released relatively few substances and in lesser amounts. Parasitoids and predators that can find their victims on all of these plants will have to deal with all this variability and are likely to show differences in their preferences for these odors based on their interactions with certain plant species over evolutionary time. One behavioral characteristic that has been frequently shown for parasitoids, and which may help them to deal with this tremendous variation, is the ability to learn by association. This ability allows parasitoid females to change their responses in accordance with the odor cues that they experience to be most reliably associated with the presence of hosts (Turlings et al., 1993b; Vet et al., 1995). This associative learning is expected to be important for generalist parasitoids, which are unlikely to rely on innate preferences for specific cues but rather need to establish what cues are most reliably associated with the presences of suitable hosts at a given time. This may be different for highly specialized parasitoids such as $C$. nigriceps, which only attacks $H$. virescens (De Moraes et al., 1998). It too relies on plant volatiles for host location but apparently has adapted to respond to subtle differences in the plants' responses to damage by different insects. It still has to be determined what these differences are. Studies on the host-locating behavior of the aphid parasitoid A. ervi suggest that it distinguishes between plants that carry host and non-host aphids with the use of a single compound, 6-methyl-5-hepten-2-one. So far, this compound has only been found in the odor blend emitted by host-infested plants (Du et al., 1998; Powell et al., 1998). Further studies with additional plant genotypes and plant species will reveal if such specific indicators are indeed provided by the plants.

\section{Benefits}

Among others, Faeth (1994), van der Meijden and Klinkhamer (2000), and Hare (2002) have stressed the need for ecological evidence that plants benefit from recruiting natural enemies of herbivores. Van der Meijden and Klinkhamer (2000), who focus on parasitoids, criticized the studies that imply mutualistic interactions between the first and third trophic level. They cite several papers on parasitoids that may not reduce herbivory in their hosts. Indeed, there are examples where plants do not benefit from the action of parasitoids (e.g. Coleman et al., 1999), but the authors overlooked most of the papers that found such a reduction in herbivory after parasitization (see Beckage, 1985). In fact, van Loon et al. (2000b) pointed out that all studied solitary parasitoids cause their hosts to feed less, whereas for 
gregarious parasitoids this can vary. However, a reduction of herbivory does not necessarily imply a fitness gain for the plant. That plant fitness can indeed increase as a result of parasitization was convincingly demonstrated by Gómez and Zamora (1994). They studied the effects of chalcid parasitoids that attack a seed weevil (Ceutorhynchus sp.) on the fitness of a woody crucifer, Hormathophylla spinosa. With exclusion experiments in the field, they were able to show that, in the presence of the parasitoids, plants that were attacked by the weevil produced more seeds per fruit than weevil-infested plants without parasitoids. The parasitoids reduced weevil-inflicted seed damage to such an extent that the plants produced almost three times as much seed (Gómez and Zamora, 1994).

For leaf-feeding insects, which have been most studied in the context of induced odors that are attractive to parasitoids, such evidence was missing until recently. In a first study, van Loon et al. (2000b) showed that Arabidopsis thaliana plants attacked by larvae of Pieris rapae (Lepidoptera: Pieridae) produced considerably more seed when the larvae were parasitized by the solitary endoparasitoid Cotesia rubecula. We obtained similar results with the maize-Spodoptera system and found that plants infested with larvae parasitized by Cotesia marginiventris yielded more seed than those attacked by healthy Spodoptera larvae (Fritzsche Hoballah and Turlings, 2001). This evidence clearly shows the potential of plant signals indirectly to reduce herbivory and enhance plant fitness, but it remains to be seen what the consequences of these interactions are for wild plants in their natural environment.

\section{Other ecological consequences of induced odor emissions}

Attraction or repellence of herbivores by induced plant odors

A limited number of studies have looked at how induced plant volatiles affect the attractiveness of herbivores. It was found that different herbivores are affected differently. Landolt (1993) showed that adult females of the cabbage looper, Trichoplusia ni (Lepidoptera: Noctuidae), may be more attracted to cotton plants that have already been damaged by its larvae, but they prefer to oviposit on healthy plants rather than damaged plants. In the case of cabbage plants, cabbage looper females avoided previously damaged plants altogether (Landolt, 1993). Repellence of plants that emit herbivore-induced volatiles was also observed for the corn-leaf aphid Rhopalosiphum maidis. This was demonstrated under laboratory as well as field conditions (Bernasconi et al., 1998).

Interestingly, Lepidoptera and aphids seem to avoid already infested plants, whereas Coleoptera are in general attracted to volatiles emitted by plants that are under attack by conspecifics. This has been shown for scarabaeid (Domek and Johnson, 1988; Harari et al., 1994; Loughrin et al., 1995b) and chrysomelid beetles (Peng and Weiss, 1992; Bolter et al., 1997; Kalberer et al., 2001). The Colorado 
potato beetle, a chrysomelid, is more attracted not only to potato plants damaged by conspecifics rather than undamaged plants (Bolter et al., 1997; Landolt et al., 1999) but also to plants treated with insect regurgitant or the synthetic elicitors of odor emissions volicitin and methyl jasmonate (Landolt et al., 1999), as well as to plants exposed to damaging ozone levels (Schutz et al., 1995). These beetles specialize on specific host plants and are well adapted to, and may even exploit, their hosts' chemical defenses. Increases in these defensive chemicals in response to damage or elicitors may not be harmful to these insects. Moreover, beetles may be less vulnerable to natural enemies, especially if they rely on plant-derived chemicals for their defense. They may, therefore, be under less or no pressure to avoid plants that emit attractants for natural enemies. It has been proposed that the beetles visiting already attacked plants increase their chances of finding a suitable mate (Loughrin et al., 1995b; Kalberer et al., 2001) and a mass attack may weaken the plants' chemical defense potential.

For some herbivores, the responses to herbivore-induced plant odors differ under different circumstances. For instance, the spider mite T. urticae is more attracted to healthy lima bean leaves than leaves that emit volatiles induced by spider mite infestation (Dicke, 1986; Dicke and Dijkman, 1992). However, Pallini et al. (1997) found that the same mite is attracted to cucumber plants that are already infested by conspecifics. In contrast, T. urticae avoids the odor of cucumber plants under attack by the western flower thrips, Frankliniella occidentalis, which is a herbivore but also feeds on spider mites. Bark beetles can cause strong reactions in their host trees, resulting in the emission of a blend of volatile terpenoids that, in combination with aggregation pheromenes, is used in mass attacks. These same substances may attract predators (Byers, 1989) and parasitoids (Sullivan et al., 2000; Pettersson, 2001; Pettersson et al., 2001) to infested trees.

As yet, there is no specific pattern in how induced volatiles affect the attractiveness of plants to herbivores. Obviously, the responses will be correlated with fitness consequences. Insects vulnerable to natural enemies and induced plant toxins are, therefore, expected to avoid induced plants, whereas those that are adapted to plant defenses and/or benefit from aggregating are likely to be attracted. Comparative studies could test such hypotheses.

\section{Plant-plant "communication”}

Evidence for interactions among plants mediated by airborne chemicals was first obtained some twenty years ago (Baldwin and Schultz, 1983; Haukioja et al., 1985; Rhoades, 1983, 1985), but skepticism and criticism of methodology and statistical procedures (Fowler and Lawton, 1985) initially prevented general acceptance by biologists. Evidence obtained since then has changed this. Ethylene was shown to activate defense genes (Ecker and Davis, 1987) and, in the seminal paper by Farmer 
and Ryan (1990), it was shown that methyl jasmonate induced the synthesis of proteinase inhibitors in tomato plants.

In the spider mite-lima bean system, it has now been shown that mite infestation activates defense genes in the plants and, in addition, several of these genes can also be activated when a lima bean plant is exposed to some of the induced volatiles of neighboring conspecifics (Arimura et al., 2000a,b). Clearly, the genetic basis for plant-plant communication is in place. That it can actually take place in the field has now also been confirmed.

Dolch and Tscharntke (2000) studied the effects of artificial defoliation of alder trees on subsequent herbivory by alder leaf beetle (Agelastica alni). After defoliation, herbivory by $A$. alni was significantly lower in the defoliated trees and its neighbors compared with trees distant from the manipulated trees. Laboratory studies confirmed that resistance was induced not only in defoliated alders but also in their undamaged neighbors (Dolch and Tscharntke, 2000). Follow-up work showed that alder leaves respond to herbivory by $A$. alni with the release of ethylene and of a blend of volatile mono-, sesqui-, and homoterpenes. This herbivory also increased the activity of oxidative enzymes and proteinase inhibitors (Tscharntke et al., 2001).

Additional convincing evidence for odor-mediated interactions between plants comes from a field study by Karban et al. (2000). They showed, over several years, that clipping sagebrush caused neighboring wild tobacco plants to become more resistant to herbivores. Preventing root contact between the plants did not change this effect, but preventing the exchange of volatiles between the plants by enclosing the clipped shoots in plastic bags did mitigate the effect. The explanation is that the release of methyl jasmonate by the damaged sagebrush caused an increase in phenol oxidase in the tobacco plants, rendering them more toxic to herbivores (Karban et al., 2000). The relevance of such interactions in natural interactions remains to be elucidated for odor emissions resulting from natural herbivory.

In the context of tritrophic interactions, plant-plant communication has been subject to only few studies (Bruin et al., 1995). In one such study, Bruin et al. (1992) demonstrated that healthy cotton plants that were exposed to spider mite-induced volatiles from conspecific plants increased in their attractiveness to predatory mites. This increased attraction was probably not simply the result of adsorbence and re-release of these volatiles from the healthy plants, because there is now clear evidence that volatiles from spider mite-infested plants can induce odor releases in neighboring plants (Arimura et al., 2000a).

\section{Inducible nutrition}

Although insect predators and parasitoids are carnivorous by definition, they often also feed on plant-derived foods. This vegetarian side to their diet includes various 
plant substrates, such as nectar, food bodies, and pollen. In addition, they often utilize foods indirectly derived from plants (e.g. honeydew, or pycnial fluid of fungi). In some cases, predators may also feed on plant productive tissue, in which case they have to be classified as potential herbivores. The level in which predators or parasitoids depend on primary consumption varies.

\section{Nutritional requirements of natural enemies}

Ants display a broad variation in lifestyles, which is reflected in an equally broad dietary diversity, ranging from species that are primarily predators to species that rely almost entirely on honeydew and extrafloral nectar. Although it has long been held that the majority of ant species are predominantly carnivorous (Hölldobler and Wilson, 1990; Sudd and Franks, 1987), Tobin (1994) argued that the dominant species are largely primary consumers, for which the bulk of their diet consists of plant-derived carbohydrates. An important dichotomy might occur between the nutrition of immature and mature stages. Ants tend to feed protein-rich food preferentially to their larvae, whereas the adults survive mostly on a diet of plant-derived carbohydrates (Haskins and Haskins, 1950; Vinson, 1968). Further differentiation takes place among the adult castes, as it is believed that certain activities such as foraging, killing, and dismemebering of prey, as well as the transporting of food items or building material, require most energy (Beattie, 1985). Foraging workers retain the majority of sugar-rich foods, while passing the bulk of protein-rich food to castes remaining in the nest (Markin, 1970; Schneider, 1972). The important role of carbohydrates to ant nutrition was also demonstrated by Porter (1989). He showed that fire ant colonies kept on insect prey only had a retarded growth and reproduction rate in comparison with colonies fed both prey and sugar water. It has been argued that displacement of the native fire ant Solenopsis geminata by the imported fire ant Solenopsis invicta is partly based on the latter species' higher efficacy in collecting liquids such as nectar (Tennant and Porter, 1991). The main carbohydrate sources exploited by ants are extrafloral nectar (Fisher et al., 1990) and honeydew, the sugar-rich excretions from sap-feeding insects (Retana et al., 1987). Interestingly, the use of floral nectar appears to be relatively uncommon (Tobin, 1994).

While sugar solutions can be a significant item in the diet of ants, parasitoids are often entirely dependent on carbohydrates as an adult food source (Jervis et al., 1993). The parasitoids' longevity and fecundity are usually subject to energetic constraints (Leatemia et al., 1995; Stapel et al. 1997; Wäckers et al., 2001), whereas the parasitoids' behavior can also be strongly affected by their nutritional state (Takasu and Lewis, 1995; Wäckers, 1994). There is strong evidence that the availability of suitable sugar sources can play a key role in parasitoid host dynamics (Krivan and Sirot, 1997; F. L. Wäckers unpublished data). 


\section{Plant-provided nutrition and its functions}

Plants employ nutritional supplements in a range of mutualistic interactions. Best known are the floral rewards targeted at pollinators (Faegri and van der Pijl, 1971), and the fleshy fruit tissue promoting seed dispersal by vertebrates. Ants as well can play an important role in the dissemination of seeds. Their tendency to harvest seeds and to transport them to their (underground) nests makes ants efficient seed dispersers (Horvitz and Schemske, 1986; Jolivet, 1998). Some plant species stimulate this interaction by producing protein- and lipid-rich seed appendages, the so-called elaiosomes (Milewski and Bond, 1982). Ants collect these seeds preferentially, consume the nutrient-rich elaiosomes and may subsequently discard the hard seeds in underground waste dumps. The scarring of the seeds, the moist and nutrientrich surroundings, as well as the clustering of seeds, might be factors benefiting germination and seedling growth (Beattie, 1985).

Defense is a further category in which plants employ food rewards to acquire protection by arthropod mutualists. The provision of food sources allows plants to recruit or sustain predators or parasitoids, which, in turn, can provide protection against herbivory. The plant-derived food structures involved in indirect defensive interaction can be divided in two main groups: food bodies and extrafloral nectaries.

Food bodies are protein- and/or lipid-rich epidermal structures, including Beltian bodies, Müllerian bodies and pearl bodies (Rickson, 1980). Food bodies can be harvested by ants for consumption by either larvae or adults. However, in some of the examples that have been described as "food bodies," actual collecting by ants has not yet be observed (Beattie, 1985). Unlike extrafloral nectar, food bodies can serve as an alternative to insect protein. However, it incurs the risk that ants become protein satiated, which may hamper carnivory. This facilitates intimate interactions with ants, as it allows ants to remain on the plant (nesting) during times in which the availability of insect protein is low. Some ant species rely entirely on food bodies of their particular host plant for their protein supply (Carroll and Janzen, 1973). Even though food bodies are collected by some non-mutualists (Letourneau, 1990), the range of potential consumers is not as broad as in the case of the easily accessible and digestible extrafloral nectar (Whitman, 1994). This makes food bodies less vulnerable to consumption by unintended consumers.

Extrafloral nectaries include a wide range of nectar-excreting structures, which are distinguished from their floral counterparts by the fact that they are not involved in pollination. Extrafloral nectar is typically dominated by sucrose and its hexose components glucose and fructose. The fact that these common sugars are acceptable to the majority of insects, combined with the exposed nature of extrafloral nectaries, makes them suitable food sources for a broad range of insects. Compared with floral nectar, extrafloral nectar often has increased fructose and glucose levels (Tanowitz 
and Koehler, 1986; Koptur, 1994), as well as a higher overall sugar concentration (Koptur, 1994; Wäckers et al., 2001). These characteristics can be explained by the exposed nature of most extrafloral nectaries, which result in faster microbial breakdown of sucrose and increased evaporation. The high sugar concentration may also serve an ecological function, as high sugar concentrations reduce intake by visiting ants and increase durations of ant visits (Josens et al., 1998). A further benefit of highly concentrated extrafloral nectar may lie in the fact that it prevents nectar use by a range of non-intended visitors (Wäckers et al., 2001). This applies especially to Lepidoptera, whose mouthpart morphologies restrict them to feeding on nectar with relatively low sugar concentrations.

In addition to carbohydrates, extrafloral nectar may contain variable amounts of proteins, amino acids, and lipids (Baker et al., 1978; Smith et al., 1990). The particular amino acid composition can increase the attractiveness of extrafloral nectar as a food source (Lanza, 1988). Nevertheless, extrafloral nectar by itself falls short from providing a well-balanced diet. Low amino acid levels or the absence of certain essential amino acids forces nectar consumers to seek out supplementary protein sources, thereby stimulating predation.

Extrafloral nectar can make a significant contribution to the diet of ant species visiting these food sources. Fisher et al. (1990) reported that the six ant species investigated in their study derive between 11 and $48 \%$ of their diet from extrafloral nectar. Retana et al. (1987) found (extrafloral) nectar to be the main food source for Camponotus foreli. Extrafloral nectar can also be extensively used by other predators (Bakker and Klein, 1992; Ruhren and Handel, 1999), as well as parasitoids (Bugg et al., 1989). In some instances, these carnivores, rather than ants, might represent the primary force protecting the plant (Ruhren and Handel, 1999; V. Rico Gray, personal communication).

\section{Constitutive versus induced extrafloral nectar}

\section{Constitutive nectar production}

Most plants excrete some extrafloral nectar irrespective of whether herbivores are present. Such constitutive nectar production may be synchronized with the most susceptible stages of plant growth (Bentley, 1977) or with the times during which damaging herbivores are usually active (Tilman, 1978). Furthermore, nectar production may coincide with the daily activity pattern of ants (Pascal and Belin-Depoux, 1991). Further synchronization is achieved through the ability of the plants to increase nectar secretion in response to herbivore presence (Koptur, 1989; Wäckers and Wunderlin, 1999; Heil et al., 2001).

In general, constitutive nectar production may provide a degree of prophylactic protection, because it allows plants to accommodate some natural enemies before 
herbivores arrive (Wäckers et al., 2001). Prophylactic protection by natural enemies may include, for example, the prevention of herbivore oviposition or removal of herbivore eggs. Maintaining some baseline nectar production in undamaged plants is also likely to assure some level of ant visitation, which expedites the defense response to herbivore attack.

\section{Induction of food provision}

In addition to the constitutive production of food supplements, some plants can actively adjust their food provision in response to their biotic environment (Table 2.2). Unlike other defense mechanisms, this induction can be elicited by two distinct mechanisms. Food provision can be raised both by food removal (Risch and Rickson, 1981; Koptur, 1992; Heil et al., 2000) and by tissue damage (Koptur, 1989; Wäckers and Wunderlin, 1999; Wäckers et al., 2001; Heil et al., 2001). These mechanisms represent active responses by the plants to both ant attendance and herbivore feeding. This receptiveness toward the presence of both the second and the third trophic level represents a unique and highly dynamic type of plant response.

In the case of food bodies, the primary mechanism of induction might be food body removal. Risch and Rickson (1981) showed that the production of unicellular food bodies by Piper cenocladum is stimulated by the presence of the mutualist ant Pheidole bicornis. When ants are present, the plant produces 30 times as many food bodies as control plants. Similar effects had previously been reported for other types of food body (Carroll and Janzen, 1973). In P. cenocladum, a clerid beetle exploits this relationship. Their larvae are also able to stimulate food body production in the absence of the ants (Letourneau, 1990).

Extrafloral nectar production can be raised in response to both nectar removal (Koptur, 1992; Heil et al., 2000) and tissue damage. Stephenson (1982), using Catalpa speciosa, was the first to investigate the latter mechanism. He diluted the nectar of individual nectaries with water and demonstrated that the diluted nectar collected from sphingid-damaged leaves was richer in solutes compared with nectar collected from undamaged leaves. Smith et al. (1990) point out that this does not resolve whether $C$. speciosa actually increased its nectar volume or whether it produced the same volume with an increased solute concentration.

Koptur (1989) reported that mechanical damage of Vicia sativa leaves increased the volume of extrafloral nectar production by a factor of 2.5. Heil et al. (2001) reported a two- to five-fold increase in volume of nectar secretion in Macaranga tanarius following leaf damage. In Ricinus communis and Gossypium herbaceum, the increase in extrafloral nectar production following S. littoralis herbivory was three-fold and ten-fold, respectively (Wäckers et al., 2001). Through parallel high pressure liquid chromatographic analysis of sugars in the collected nectar, the 


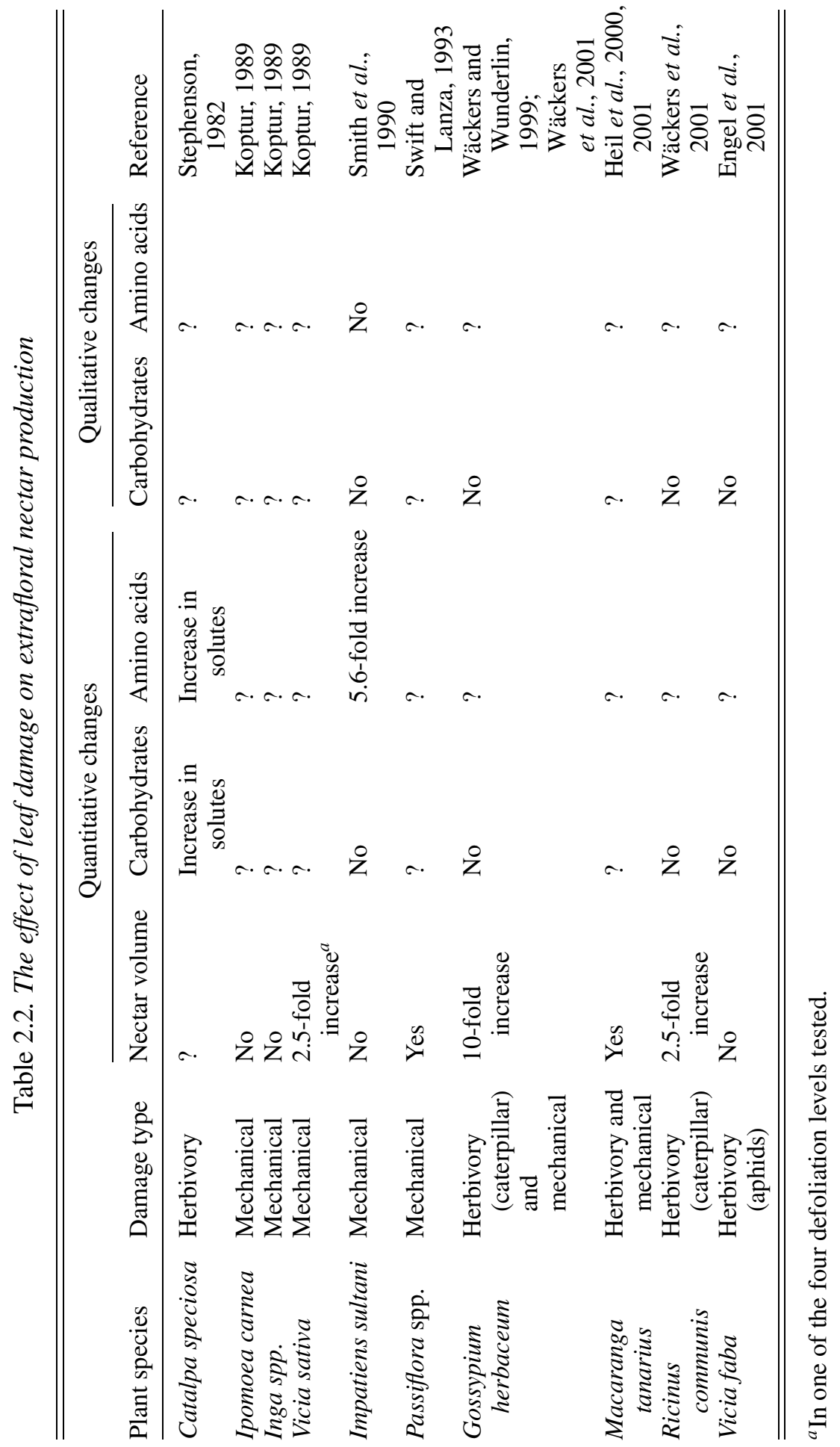


latter study was the first to demonstrate that the increased nectar secretion actually represents a proportionate increase in carbohydrate secretion.

All these examples focus on the temporal aspect of nectar induction. In addition, extrafloral nectaries are also especially suited for the study of spatial dynamics following induction. This aspect can be easily assessed because of the discrete distribution of nectaries, the possibility of non-destructive sampling, as well as the ease of nectar collection. With respect to the spatial pattern of induction, Wäckers et al. (2001) showed that the impact of herbivory on extrafloral nectar induction is primarily localized (i.e., restricted to the damaged leaf). This local increase in nectar production can help in actively guiding ants to the site of attack. In addition, a weaker systemic response was found. This systemic induction was restricted to the younger leaves.

These examples show that several plants possess the ability to raise extrafloral nectar production in response to herbivory, but this induction is not necessarily universal and might vary depending on both plant and herbivore species (Table 2.2). Koptur (1989) could not demonstrate an effect of mechanical defoliation on extrafloral nectar production in Ipomoea carnea, Inga brenesii and Inga punctata. In $V$. faba, aphid feeding had no effect on the quantity of extrafloral nectar secretion (Engel et al., 2001). A similar lack of induction was found following feeding by S. littoralis larvae (F. L. Wäckers, unpublished data).

\section{Specificity of induction: elicitors and mechanisms}

The few studies that have addressed the induction of extrafloral nectar production have examined either actual herbivory or mechanical damage. The fact that mechanical damage failed to elicited nectar induction in several plant systems (Koptur, 1989) could be interpreted as indicating that the method of mechanical damage is not a suitable mimic of herbivory.

Induction of nectar secretion could require a herbivory-specific elicitor, similar to the induction of plant volatiles. To investigate this Wäckers and Wunderlin (1999) conducted a set of experiments analogous to those conducted by Turlings et al. (1990), in which cotton plants were subjected either to herbivory or to mechanical damage with and without caterpillar regurgitant. In contrast to the mechanism of herbivore-induced volatile emission, the induction of extrafloral nectar secretion was found to be elicited by tissue damage, irrespective of whether this damage was mechanical or caused by actual herbivory. The addition of $S$. littoralis regurgitant had no significant effect on the level, the timing, or the distribution of nectar secretion. These findings indicate that the induction of extrafloral nectar secretion constitutes a general response by the plant to tissue damage, rather than representing a herbivory-specific mechanism. 
This rather unspecific induction of nectar secretion in cotton was surprising in light of the fact that the induction of volatile emission by this plant had been demonstrated to be specific. Herbivore-damaged plants show a higher rate of volatile emission compared with mechanically damaged plants (McCall et al., 1994), and herbivore feeding induced de novo synthesis of various terpenoids (Paré and Tumlinson, 1997), which resulted in a quantitative as well as a qualitative response to herbivory. The specificity of the plant response is not restricted to the differentiation between mechanical damage and herbivory. The composition of the induced volatile blend also varies between (even closely related) herbivore species (De Moraes et al., 1998).

The difference in induction specificity between the two categories of indirect defense indicates that the induction pathways involved are not entirely identical. It may also reflect differences in the costs and benefits of such specificity (Wäckers and Wunderlin, 1999). The use of volatiles as a signal to recruit natural enemies is dependent on induction, as this communication between plants and the third trophic level breaks down when the volatile signal is not reliably associated with herbivore presence. Extrafloral nectar, by comparison, constitutes a reward in itself rather than serving as a signal to indicate the location of a reward. The response by the third trophic level, as a result, is not dependent on the degree in which nectar secretion correlates with herbivore presence. Therefore, an increase in nectar production following mechanical damage entails the additional cost of nectar production but has no negative implications for the efficacy of this indirect defense mechanism.

Working with M. tanarius, Heil et al. (2001) also reported that mechanical damage is sufficient to induce nectar secretion. They were also able to achieve a similar response through exogenous application of JA to undamaged plants. This fact, combined with the finding that the response in damaged plants could be suppressed by phenidone, an inhibitor of JA synthesis, indicates that the induction of extrafloral nectar production is elicited via the octadecanoid signal cascade (Heil et al., 2001), which is also involved in the production of various inducible plant volatiles (see above).

\section{Costs and benefits}

The benefit of extrafloral nectar production to plant fitness has been well established (Bentley, 1977; Inouye and Taylor, 1979; O’Dowd, 1979; Wagner, 1997; Koptur et al., 1998). Whether induction further enhances plant fitness over constitutive nectar production remains an open issue. The fact that both inducible and constitutive nectar production occurs (Table 2.2) indicates that the costs and benefits of nectar induction vary among plants.

It is often believed that the primary benefit of induction is economical, as it restricts defensive investments to those periods in which plants are actually under 
attack (Rhoades, 1979; Zangerl and Rutledge, 1996). In addition to these economic benefits, induction of extrafloral nectar production may also enhance the effectiveness of natural enemy recruitment, because it results in an accumulation of natural enemies on the site of attack (F. L. Wäckers and F. Frei, unpublished data). However, these benefits of induction come at the price of increased vulnerability during the plant's non-induced state. To understand the pattern in which extrafloral nectar is produced, we need to identify and quantify the particular costs involved in the use of this indirect defense.

\section{Costs of extrafloral nectar production}

Pyke (1991) demonstrated a trade-off between floral nectar secretion and seed production in hand-pollinated Brandfordia nobilis. Comparable studies on fitness consequences of extrafloral nectar production have yet to be conducted. However, strong indirect evidence for the high cost of extrafloral nectar production is provided by the finding that some plant species have lost extrafloral nectaries in ecosystems void of mutualist ant species. Rickson (1977) was able to track the gradual regression of Cecropia peltata extrafloral nectaries from Azteca ant-inhabited mainland Central America over a range of Caribbean islands lacking the mutualist ant species. Bentley (1977) described a decline in sepal nectaries of Bixa orellana from ant-rich lowlands to higher altitudes where ant populations are scarce.

\section{Direct costs}

To the plant, the direct cost of producing extrafloral nectar can be relatively low. O'Dowd (1979) estimated that the energy invested in the lifetime petiolar nectar production of an individual Ochroma pyramidale leaf constitutes about $1 \%$ of the leaf's energy content. However, since leaf tissue makes up only part of the total plant mass, this figure does not reveal which fraction of the total assimilated energy is diverted to extrafloral nectar. A more accurate way to estimate allocational costs is to express the quantity of excreted sugars as a fraction of the daily production of assimilates. Wäckers et al. (2001) calculated that castor (Ricinus communis) diverts $0.9 \%$ of its daily assimilates to the production of extrafloral nectar. Even though this cost may seem unsubstantial, its cumulative nature could lead to rapid cost increments over the total period of plant growth. In addition to the loss of carbohydrates, nectar secretion also entails a loss of other compounds, in particular amino acids and water. Depending on the growth conditions of the plant, loss of these compounds may represent considerable additional cost factors.

Direct costs also include the costs involved in active nectar sequestration, as well as the cost involved in producing the nectary. This latter cost is probably low, as nectaries are often simple and small, showing little differentiation. In other types of defense, costs relating to biosynthesis, transport, and storage (i.e., autotoxicity) can 
be considerable (Karban and Baldwin, 1997). However, these costs do not apply in the case of extrafloral nectar as nectaries are usually vascularized and obtain non-toxic primary metabolites directly from the phloem or xylem (Frey-Wyssling, 1955; Beattie, 1985).

\section{Ecological costs}

In addition to the direct costs, the production of extrafloral nectar can also entail substantial indirect (ecological) costs. In insect-pollinated plants, extrafloral nectaries can have adverse effects on pollination efficacy. Interference with the pollination process can occur when extrafloral nectaries distract the pollinators away from the floral nectar (Koptur, 1989) or when nectary-attending ants attack flower visitors (F. L. Wäckers personal observation). Considerable ecological costs may arise when extrafloral nectaries are exploited by herbivores. Adult herbivores such as moths are often entirely or partly dependent on sugar solutions as an energy source. Nectar feeding frequently increases herbivore longevity as well as the number and size of matured eggs (Leahy and Andow, 1994; Binder and Robbins, 1996; Romeis and Wäckers, 2000, 2002). When herbivores are attracted or retained by extrafloral nectaries, this can severely increase herbivory levels on nectar-producing plants (Adjei-Maafo and Wilson, 1983; Rogers, 1985; McEwen and Liber, 1995). To reduce these ecological costs, plants may have adapted the extrafloral nectar composition to exclude unintended visitors and to cater selectively to those insects from which they benefit (Wäckers et al., 2001).

How heavily these direct and indirect cost factors weigh on plant fitness depends on the plant species and its growing conditions. Induction of extrafloral nectar production, however, allows plants to minimize almost all of these cost factors simultaneously. In the absence of herbivory, nectar production and its associated costs may be all but eliminated, with the full costs only being assumed during periods of herbivory.

The cost-saving benefit of inducible defense is counterbalanced by the loss of preventative protection (Zangerl and Bazzaz, 1992). Any damage inflicted during the lag period between herbivore attack and the onset of the induced defense should be included in the costs of induction. It is our experience that the induced production of nectar takes about $24 \mathrm{~h}$ (Wäckers et al., 2001). In the economic terms of the optimal defense theory, inducible defenses have a selective advantage over constitutive defenses when the savings in defensive costs during herbivore-free periods outweigh the loss in preventative protection during the lag time of induction. In comparison with direct defenses, lag time of indirect defense is extended because of the inherent delay in natural enemy response. In the case of ants responding to extrafloral nectaries, this delay includes the time for ant scouts to encounter the nectary, as well as the time required for nestmate recruitment (Wäckers et al., 
2001). This additional lag time likely reduces the economic benefits of induction of indirect defenses relative to those of direct defense. Plants may have developed various strategies to minimize the lag time of indirect defense induction. Maintaining some baseline nectar production in undamaged plants could be such a strategy. By accommodating at least a few natural enemies, the indirect defense can begin to operate quickly once the plant is attacked.

\section{The need for more field data}

To demonstrate that a plant trait has a defensive function, it is necessary to show that it has a negative effect on plant antagonists, reduces the damage done to the plants, and increases plant fitness under natural conditions (Hare, 2002). Attraction of natural enemies to herbivore-induced volatiles has mainly been demonstrated in laboratory studies, and the role of these volatiles for interactions in the field is still poorly understood (Sabelis et al., 1999). Initial evidence comes from studies in which caged plants out in a field were found to attract more parasitoids or predators when damaged by herbivores than when undamaged. Drukker et al. (1995) showed that psyllid-infested pear trees attracted more predatory anthocorid bugs than trees without psyllids. In the laboratory, Scutareanu et al. (1997) demonstrated that infested trees release more and different volatiles than uninfested pear trees, and that the production of these volatiles was positively correlated with the density of the psyllids on the trees. Similar results were obtained by Shimoda et al. (1997), who found in a field experiment that the predator Scolothrips takahashii was attracted to cages that contained a lima bean plant infested with spider mites. Spider mite infestation is known to cause lima bean to emit a blend of specific terpenoids and methyl salicylate (Dicke and Sabelis, 1988; Dicke et al., 1990a,b). However, as for the study with the psyllid-infested pear trees, it could not be excluded that the predators were directly attracted by the herbivores on the plants rather than the induced plant odor.

Conclusive field evidence has been obtained with the manipulation of odor emissions of free-standing plants. Thaler (1999), for example, observed an increase in parasitism of $S$. exigua larvae on tomato after the plants had been treated with JA. This treatment induces the octadecanoid pathway, which results in the production of various defense compounds, including volatiles. In an earlier study in a tobacco field, De Moraes et al. (1998) had already found that the specialist parasitoid C. nigriceps could distinguish between the odor of plants that have been damaged by its specific host $H$. virescens and the odor of plants damaged by a closely related non-host. In a natural, non-agricultural environment, Kessler and Baldwin (2001) supplemented the odor of wild tobacco plants with synthetic volatiles and found that $(Z)$-3-hexenol, linalool and $(Z)-\alpha$-bergamotene all increased the predation rate 
of $M$. sexta eggs and neonate larvae by a generalist predator. Similar increases of predation were obtained by treating wild tobacco plants with methyl jasmonate (Kessler and Baldwin, 2001). In one of our own studies, we trapped considerably more parasitoids on sticky traps downwind from maize plants treated with caterpillar regurgitant than upwind from these plants or near untreated plants (Bernasconi Ockroy et al., 2001). These studies provide good evidence for a role of induced plant volatiles in host and prey location. What is still missing, however, is field evidence from unmanipulated studies showing that plants actually benefit from these interactions.

The sophisticated equipment required for volatile identification has long confined the topic of herbivore-induced volatiles to the laboratory, but extrafloral nectaries have traditionally been studied in the field. Moreover, the work on extrafloral nectaries has mainly addressed wild plant species within their natural habitat, whereas the study of plant volatiles has long focussed on agricultural crops. As a result, we have a relative wealth of field evidence for the defensive function of extrafloral nectaries.

It has been well established that extrafloral nectaries are visited by a range of predators and parasitoids (Janzen, 1966; Bugg et al., 1989; Koptur, 1992). Ants are by far the most common visitors to extrafloral nectaries. The facts that ants are social, show recruitment behavior, and have a strong tendency to defend lucrative sugar sources against competitors make them especially suitable as defensive agents. Nevertheless, not all ants are equally effective. Their aggressiveness ranges from species that attack large mammals (Bennett and Breed, 1985) to species that are passive or even tend to drop from the nectary when disturbed (O'Dowd, 1979).

In a number of cases, it has been demonstrated that increased levels of nectar production translates to higher levels of ant attendance (Passera et al., 1994). The fact that the most aggressive ants monopolize the most productive nectar sources (Del-Claro and Oliveira, 1993) constitutes a further benefit to high levels of nectar production.

Using exclusion experiments, several studies were able to demonstrate that ants effectively protect the plant against herbivory (O'Dowd and Catchpole, 1983; Wagner, 1997; but see O'Dowd and Catchpole, 1983; Rico-Gray and Thien, 1989). In the same way, reduction of herbivory has recently been demonstrated in mutualisms between extrafloral nectaries and spiders (Ruhren and Handel, 1999), as well as predatory wasps (V. Rico-Gray, personal communication).

A number of studies have provided the ultimate proof for the defensive function of extrafloral nectaries by demonstrating that herbivory reduction by ants actually translates to an increased reproductive fitness of nectar-providing plants (Koptur, 1979; Rico-Gray and Thien, 1989; Oliveira, 1997; Wagner, 1997). In the most 
extreme cases, unattended plants die as result of herbivory in the absence of ants (Janzen, 1966).

In addition to these empirical studies, there is indirect ecological evidence for the defensive function of extrafloral nectaries. Several studies have reported correlations between the abundance of plants with extrafloral nectaries and ant abundance (Pemberton, 1998; Rico-Gray et al., 1998). Bentley (1977) and Rickson (1977) showed that plants may lose extrafloral nectaries in ecosystems void of mutualist ant species.

Even though this evidence supports the defensive function of extrafloral nectaries, the evidence is largely based on myrmecophilous plants. In other plant species, the benefit of ant attendance is not always as clear (O'Dowd and Catchpole, 1983; Koptur and Lawton, 1988). In these species, the provision of extrafloral nectar may serve to enhance the effectiveness of other plant-predator (Ruhren and Handel, 1999) or plant-parasitoid interactions (Lingren and Lukefahr, 1977; Bugg et al., 1989; Koptur, 1994), or serve other (non-defensive) functions.

\section{Future directions}

Although much is known about various intricacies of the active role of plants in tritrophic interactions, it is evident from the above review that numerous questions remain and several areas are virtually unexplored. We identify three areas that appear to us as particularly interesting and they can be expected to receive special attention in future research programs.

\section{Cross-effects}

Almost all studies on induced indirect defenses have looked at the effects of an attack by a single herbivore or pathogen species. In a natural situation, however, plants often suffer from simultaneous attacks by multiple adversaries. Many plants carry several herbivores and they can be infested by pathogens at the same time that they are eaten by herbivores. This should again contribute to the variability of reactions that plants exhibit. Plant infestations by multiple species and their crosseffects have been studied for direct defenses (Hatcher, 1995; Agrawal et al., 1999; Rostàs et al., 2003), but not yet in the context of indirect defenses.

Studies on the cross-effects of herbivore and pathogen infestation on direct defenses have yielded results that can be quite different for different systems (Karban and Kuc, 1999; Stout and Bostock, 1999; Rostàs et al., 2003). The cucumber plant has been studied in detail with several pathogens and herbivores (Apriyanto and Potter, 1990; Ajlan and Potter, 1991; Moran, 1998). In most cases, infection with one pathogen caused a systemic resistance to other pathogens but had no 
systemic effect on insect herbivores, except for a positive effect on the striped cucumber beetle (Apriyanto and Potter, 1990). Moran (1998) reported that locally, at the site of pathogen infestation, both positive and negative effects on insects may occur. The most extensively studied system is that of Rumex spp. attacked by the leaf beetle Gastrophysa viridula and the biotrophic rust fungus Uromyces rumicis. Hatcher and co-workers (Hatcher et al., 1994a,b, 1995; Hatcher and Paul, 2000) found that fungus infection made Rumex plants less preferred for oviposition and consumption by the beetle and, vice versa, that plants subjected to leaf beetle damage were less prone to rust infection. The studies reviewed by Rostàs et al. (2003) showed a general tendency of adverse effects of plant antagonists on each other. Very little information is available on how such cross-effects affect tritrophic interactions.

How does pathogen infestation affect odor emissions and does it interfere with emissions induced by insect herbivores? So far, only one study has specifically looked at this cross-effect (Cardoza et al., 2002). It showed that insect feeding (beet armyworm, S. exigua) and fungus infection (white mold, Sclerotium rolfsii) resulted in distinctly different odor blends in peanut plants, whereas plants that were simultaneously infested by these two antagonists released a mix of both blends.

Shiojiri et al. $(2001,2002)$ revealed a fascinating cross-effect resulting from simultaneous feeding by larvae of two lepidopteran species. They showed that Plutella xylostella and P. rapae caused cabbage plants to release different odor blends that could be distinguished by Cotesia plutella. Costesia glomerata females were only attracted by plants damaged by $P$. xylostella and not by those damaged by $P$. rapae, which it cannot parasitize. Interestingly, the parasitoid is also less attracted to plants infested by both herbivores. This could explain why adult $P$. xylostella females show a preference to oviposit on plants that have already been infested by P. rapae (Shiojiri et al., 2002),

How can multiple infestations affect each other? JA has typically been assumed to be involved in induced responses to herbivory and SA was assumed to be involved in most responses to pathogen infection. The interactions are not as straightforward and various insects and pathogens differ in the defense genes they activate (Walling, 2000). Ozawa et al. (2000) compared the induction of volatiles in lima bean leaves by caterpillars and spider mites with induction with JA and methyl salicylate. Their results suggest that response to caterpillar feeding involves the JA-related signaling pathway and that spider mite feeding triggers both the SA- and JA-related signaling pathways. Dicke et al. (1999) had already shown that JA-triggered emissions in lima bean showed some differences from mite-induced emissions and concluded that the induction involves more than just JA. This might indicate that the reaction to spider mite feeding is more similar to the reaction triggered by sucking insects 
such as whiteflies and aphids (Walling, 2000). A crucial issue in these types of study is how elicitors are applied (Schmelz et al., 2001); ideally, the treatment should reflect natural conditions. The involvement of various pathways that can be triggered differently by different plant antagonists implies that infestation by multiple organisms will add to the variability in plant responses. In light of the likelihood that plants are subject to attack by more than one adversary, it seems pertinent to study further this so-called cross-talk and its ecological implications.

\section{Exploitation of induced defenses for biological control}

The above examples illustrate how plant attributes may contribute to successful prey location by natural enemies and it has been suggested that these attributes may be exploitable in pest control (Bottrell et al., 1998; Lewis et al., 1998; Cortesero et al., 2000). It has been long recognized that efficacy of adult natural enemies as biological agents against insect pests may be increased by supplying them with food sources. Reviews on how plant-provided nutrition may aid in biological control are presented by Hagen (1986), Whitman (1994), Jervis and Kidd (1996), and Cortesero et al. (2000). Several examples show that predation and parasitism are higher on plants with extrafloral nectar than on plants without extrafloral nectar (Treacy, et al., 1986; Pemberton and Lee, 1996). Clearly, there is the potential that the production of extrafloral nectar could be optimized to increase the efficiency of biological control agents. Such selection or manipulation programs should also account for the risk that the nectar can be exploited by phytophagous insects (Rogers, 1985; Schuster and Calderon, 1986).

After it was recognized that plant volatiles play an essential role in host location by various parasitoids, it has been suggested that emission of these cues could be manipulated to facilitate prey finding and thus improve biological control (e.g., Nordlund et al., 1988; Dicke et al., 1990a; Turlings and Benrey, 1998; Cortesero et al., 2000). The potential of such an approach remains unexplored, but two of the above mentioned field studies suggest that it is feasible. Thaler's (1999) treatment of tomato plants with JA increased parasitism of an important pest. Equally promising is the increased predation of M. sexta eggs and neonate larvae that Kessler and Baldwin (2001) observed after supplementing the odor of wild tobacco plants with synthetic volatiles or by treating wild tobacco plants with methyl jasmonate. The possibilities offered by biotechnology will certainly make it possible to tailor the odor production of crop plants. The challenge will be to determine which odor blends are most effective in attracting the right control agents and again to avoid attracting herbivores at the same time.

Genetic transformation of plants for the purpose of enhancing biological control will still be some time away. These traits, however, could be well suited for the 
development of methods for the evaluation of other transgenic crops, as discussed in the next section.

\section{Evaluation of transgenic crops}

Current controversy over the use of transgenic crops places much emphasis on their potential effects on non-target insects. Various direct and indirect effects on natural enemies that are important in pest control are possible (Schüler et al., 1999a) and a number of studies have addressed these potential effects. Most of these studies have involved $B t$ maize (maize plants producing a Bacillus thuringiensis toxin) and have shown little or no negative effect of $B t$ maize (e.g., Orr and Landis, 1997; Pilcher et al., 1997). A notable exception is the reduced development and increased mortality of the predatory lacewing Chrysoperla carnae when it consumes Bt maize-fed prey (Hilbeck et al., 1998).

We are aware of only one study that has looked at the attractiveness of transgenic plants to natural enemies. Schüler et al. (1999b) studied the attractiveness of $B t$ oilseed rape to the parasitoid Cotesia plutellae, which attacks the diamondback moth ( $P$. xylostella), an important pest. As expected, feeding by the susceptible $P$. xylostella larvae was much reduced, resulting in fewer odors being emitted and a reduced attractiveness to the parasitoids. However, the outcome of this study was favorable in the sense that caterpillar-induced emissions of attractive volatiles was highest when $B t$-resistant $P$. xylostella larvae were feeding on the plants. The authors argue that this could reduce the development of resistance to transgenic plants in field situations (Schüler et al., 1999b).

For the evaluation of possible pleiotropic effects (side-effects resulting from genes effecting more than one phenotypic trait) in transgenic crops, the analyses of plant-produced odors and exudates (such as extrafloral nectar) may be ideal. Significant changes in biochemical pathways would likely result in alterations in the production of these secondary plant metabolites. Careful analyses of a large range of conventional varieties of a particular crop would also reveal the existing natural variation and would allow for a more realistic comparison than is commonly made. The significance in any observed changes for the interactions between the crop and beneficial insects could then be tested in appropriate bioassays. In such assays, conventional crops that exhibit clear differences in the trait under investigation (e.g., attractiveness to parasitoids or nutritional value of extrafloral nectar) could serve as realistic controls. For maize, we already have ample information on the considerable variation among genotypes in the emissions of volatiles (Gouinguené et al., 2001 and unpublished data). In most cases, it is not to be expected that transgenesis has a major effect on the composition of odor blends or extrafloral nectar, as the production of, for instance, $B t$ involves entirely different biochemical pathways. Herbicide resistance in maize, however, does involve the shikimate pathway (Shah et al., 1986; Padgette et al., 1994), which is responsible for the production of 
several aromatic volatiles that are induced after insect attack (Paré and Tumlinson, 1999). It would be interesting to investigate if transgenic plants with herbicide resistance produce more or less of these substances and if this has any consequences for the attraction of parasitoids and predators. It would be equally interesting to study potential changes in the carbohydrate and amino acid composition of plant nectar and honeydew resulting from transgenesis. In all cases, it will be pertinent to compare such changes with the full spectrum of existing variability and to determine the ecological relevance of the changes.

\section{Conclusions}

Extrafloral nectar and plant odors play essential roles in the protection of plants from herbivores by natural enemies. Both these traits can be inducible, but plants without insect damage may have nectaries that produce significant amounts of nectar, whereas most undamaged plants are virtually odorless compared with damaged plants. The induction of plant odor emissions is relatively specific for insect feeding, and in some cases plants respond differentially to different herbivores. So far, studies into specificity have not addressed the considerable variation in signals emitted by different plant genotypes. There appears to be a danger of overinterpreting results from experiments conducted with just one insect-plant combination. Not only can different plant genotypes differ considerably in their induced responses (e.g., Gouinguené et al., 2001; Krips et al., 2001), but, in addition, the arthropods that make use of plant signals and food may show variation and rapid genetic changes in their responses (Margolies et al., 1997; Maeda et al., 1999; Dicke et al., 2000). This variation needs to be considered and included in studies on specificity.

Both indirect defenses have now been shown to function in field situations, but further field studies are needed to confirm that plants do indeed benefit from emitting induced odors in natural settings. Moreover, nothing is yet known about the crosseffects of multiple infestations on plant indirect defenses. Also still lacking are appropriate field tests for the evaluation of plant-odor manipulation to enhance the effectiveness of biological control agents. However, various studies have indicated the potential of such approaches. Current biotechnology techniques offer ample opportunities for the manipulation of indirect plant defenses, which should largely facilitate the design of experiments that can help to answer the remaining questions on their function and exploitability.

\section{Acknowledgments}

We are grateful to Hans Alborn, Göran Birgersson, Cristina Faria, Monika Frey, Jonathan Gershenzon, Bernd Hägele, Yonggen Lou, Michael Rostàs, Goede Schüler and Cristina Tamò for advice and information on specific topics that are discussed 
in this chapter. Cristina Tamò also provide editorial assistance. This work is in part supported by funds from the Swiss National Science Foundation (grants 31-4623795 and 31-58865-99) and the Swiss Center of Competence in Research on "Plant Survival."

\section{References}

Adjei-Maafo, I. K. \& Wilson, L. T. (1983). Factors affecting the relative abundance of arthropods on nectaried and nectariless cotton. Environmental Entomology 12: 349-352.

Agelopoulos, N. A. \& Keller, M. A. (1994). Plant-natural enemy association in the tritrophic system Cotesia rubecula-Pieris rapae-Brassicaceae (Cruciferae). III: Collection and identification of plant and frass volatile. Journal of Chemical Ecology 20: $1955-1967$.

Agrawal, A. A. \& Karban, R. (1999). Why induced defenses may be favored over constitutive strategies in plants. In The Ecology and Evolution of Inducible Defenses, eds. R. Tollrian \& C. D. Harvell, pp. 45-61. Princeton: Princeton University Press.

Agrawal, A. A. \& Rutter, M. T. (1998). Dynamic anti-herbivore defense in ant-plants: the role of induced responses. Oikos 83: 227-236.

Agrawal, A. A., Tuzun, S. \& Bent, E. (1999). Induced Plant Defenses Against Pathogens and Herbivores. St Paul, MO: APS Press.

Ajlan, A. M. \& Potter, D. A. (1991). Does immunization of cucumber against anthracnose by Colletotrichum lagenarium affect host suitability for arthropods. Entomologia Experimentalis et Applicata 58: 83-91.

Alborn, H. T., Turlings, T. C. J., Jones, T. H., Stenhagen, G., Loughrin, J. H. \& Tumlinson, J. H. (1997). An elicitor of plant volatiles from beet armyworm oral secretion. Science 276: 945-949.

Alborn, H. T., Jones, T. H., Stenhagen, G. S. \& Tumlinson, J. H. (2000). Identification and synthesis of volicitin and related components from beet armyworm oral secretions. Journal of Chemical Ecology 26: 203-220.

Apriyanto, D. \& Potter, D. A. (1990). Pathogen-activated induced resistance of cucumber: response of arthropod herbivores to systemically protected leaves. Oecologia $\mathbf{8 5}$ : 25-31.

Arimura, G., Ozawa, R., Shimoda, T., Nishioka, T., Boland, W. \& Takabyashi, J. (2000a). Herbivory-induced volatiles elicit defence genes in lima bean leaves. Nature 406: 512-515.

Arimura, G., Tashiro, K., Kuhara, S., Nishioka, T., Ozawa, R. \& Takabayashi, J. (2000b). Gene responses in bean leaves induced by herbivory and by herbivore-induced volatiles. Biochemical and Biophysical Research Communications 277: 305-310.

Arthur, A. P. (1962). Influence of host tree on abundance of Itoplectis conquistor (Say) (Hymenoptera: Ichneumonidae), a polyphagous parasite of the Europeane pine shoot moth, Ryacionia buoliana (Schiff) (Lepidoptera: Olethreutidae). Canadian Entomologist 94: 337-347.

Aukema, B. H., Dahlsten, D. L. \& Raffa, K. F. (2000). Improved population monitoring of bark beetles and predators by incorporating disparate behavioral responses to semiochemicals. Environmental Entomology 29: 618-629. 
Baker, D. A., Hall, J. L. \& Thorpe, J. R. (1978). Study of extrafloral nectaries of Ricinus communis. New Phytologist 81: 129-137.

Bakker, F. M. \& Klein, M. E. (1992). Transtrophic interactions in Cassava. Experimental and Applied Acarology 14: 293-311.

Baldwin, I. T. (1994). Chemical changes rapidly induced by folivory. In Insect-Plant Interactions, vol. V., ed. E. A. Bernays, pp. 1-23. Boca Raton, FL: CRC Press.

Baldwin, I. T. \& Preston, C. A. (1999). The eco-physiological complexity of plant responses to insect herbivores. Planta 208: 137-145.

Baldwin, I. T. \& Schultz, J. C. (1983). Rapid changes in tree leaf chemistry induced by damage: evidence for communication between plants. Science 221: 277-279.

Barbosa, P. \& Saunders, J. A. (1985). Plant allelochemicals: linkage between herbivores and their natural enemies. In Chemically Mediated Interactions Between Plants and Other Organisms, eds. G. A. Cooper-Driver \& T. Swain, pp. 197-137. New York: Plenum Press.

Beattie, A. J. (1985). The Evolutionary Ecology of Ant-Plant Mutualisms. Cambridge: Cambridge University Press.

Beckage, N. E. (1985). Endocrine interactions between endo-parasitic insects and their hosts. Annual Review of Entomology 30: 371-413.

Belt, T. (1874). The Naturalist in Nicaragua. London: J. Murray.

Bender, C., Bailey, A. M., Jones, W. et al. (1996). Biosynthesis and regulation of the phytotoxin coronatine in Pseudomonas syringae. In Molecular Aspects of Pathogenicity and Host Resistance Requirement for Signal Transduction, eds. D. Mills, H. Kunoh, S. Mayama \& N. Keen, pp. 233-244. St Paul, MO: APS Press.

Bennett, B. \& Breed, M. D. (1985). On the association between Pentaclethra macroloba (Mimosacea) and Paraponera clavata (Hymenoptera: Formicidae) colonies. Biotropica 17: 253-255.

Benrey, B., Denno, R. F. \& Kaiser, L. (1997). The influence of plant species on attraction and host acceptance in Cotesia glomerata (Hymenoptera: Braconidae). Journal of Insect Behavior 10: 619-630.

Bentley, B. L. (1977). Extra-floral nectaries and protection by pugnacious bodyguards. Annual Review of Ecology and Systematics 8: 407-427.

Bernasconi, M. L., Turlings, T. C. J., Ambrosetti, L., Bassetti, P. \& Dorn, S. (1998). Herbivore-induced emissions of maize volatiles repel the corn leaf aphid, Rhopalosiphum maidis. Entomologia Experimentalis et Applicata 87: 133-142.

Bernasconi Ockroy, M. L., Turlings, T. J. C., Edwards, P. J. et al. (2001). Response of natural populations of predators and parasitoids to artificially induced volatile emissions in maize plants (Zea mays L.). Agricultural and Forest Entomology 3: $1-10$.

Binder, B. F. \& Robbins, J. C. (1996). Age- and density-related oviposition behavior of the European corn borer, Ostrinia nubilalis (Lepidoptera: Pyralidae). Journal of Insect Behavior 9: 755-769.

Boland, W. \& Gäbler, A. (1989). Biosynthesis of homoterpenes in higher-plants. Helvetica Chimica Acta 72: 247-253.

Boland, W., Feng, Z., Donath, J. \& Gäbler, A. (1992). Are acyclic C-11 and C-16 homoterpenes plant volatiles indicating herbivory? Naturwissenschaften 79: 368-371.

Boland, W., Hopke, J., Donath, J., Nuske, J. \& Bublitz, F. (1995). Jasmonic acid and coronatin induce odor production in plants. Angewandte Chemie: International Edition in English 34: 1600-1602. 
Boller, T. (1991). Ethylene in pathogenesis and disease resistance. In The Plant Hormone Ethylene, eds. A. K. Matoo \& J. C. Suttle, pp. 293-314. Boca Raton, FL: CRC Press.

Bolter, C. J., Dicke, M., Vanloon, J. J. A., Visser, J. H. \& Posthumus, M. A. (1997). Attraction of Colorado potato beetle to herbivore-damaged plants during herbivory and after its termination. Journal of Chemical Ecology 23: 1003-1023.

Bones, A. M. \& Rossiter, J. T. (1996). The myrosinase-glucosinolate system, its organisation and biochemistry. Physiologia Plantarum 97: 194-208.

Bottrell, D. G., Barbosa, P. \& Gould, F. (1998). Manipulating natural enemies by plant variety selection and modification: a realistic strategy? Annual Review of Entomology 43: $347-367$.

Bouwmeester, H. J., Verstappen, F. W. A., Posthumus, M. A. \& Dicke, M. (1999). Spider mite-induced (3S)- $(E)$-nerolidol synthase activity in cucumber and lima bean. The first dedicated step in acyclic C11-homoterpene biosynthesis. Plant Physiology 121: 173-180.

Broadway, R. M., Duffey, S. S., Pearce, G. \& Ryan, C. A. (1986). Plant proteinase-inhibitors: a defense against herbivorous insects. Entomologia Experimentalis et Applicata 41: 33-38.

Bruin, J., Dicke, M. \& Sabelis, M. W. (1992). Plants are better protected against spider-mites after exposure to volatiles from infested conspecifics. Experientia 48 : 525-529.

Bruin, J., Sabelis, M. W. \& Dicke, M. (1995). Do plants tap Sos signals from their infested neighbors. Trends in Ecology and Evolution 10: 167-170.

Bugg, R. L., Ellis, R. T. \& Carlson, R. W. (1989). Ichneumonidae (Hymenoptera) using extrafloral nectar of faba bean (Vicia faba L., Fabaceae) in Massachusetts. Biological Agriculture and Horticulture 6: 107-114.

Byers, J. A. (1989). Chemical ecology of bark beetles. Experientia 45: 271-283.

Cardoza, Y. J., Alborn, H. T. \& Tumlinson, J. H. (2002). In vivo volatile emissions from peanut plants induced by simultaneous fungal infection and insect damage. Journal of Chemical Ecology 28: 161-174.

Carroll, C. R. \& Janzen, D. H. (1973). Ecology of foraging by ants. Annual Review of Ecology and Systematics 4: 231-257.

Chen, H., Lou, Y. \& Cheng, J. (2002). Behavioral responses of the larval parasitoid Cotesia chilonis to the volatiles from its host and host plant. Acta Entomologica Sinica 45: 617-622.

Coleman, R. A., Barker, A. M. \& Fenner, M. (1999). Parasitism of the herbivore Pieris brassicae L. (Lep., Pieridae) by Cotesia glomerata L. (Hym., Braconidae) does not benefit the host plant by reduction of herbivory. Journal of Applied Entomology (Zeitschrift für Angewandte Entomologie) 123: 171-177.

Cortesero, A. M., Stapel, J. O. \& Lewis, W. J. (2000). Understanding and manipulating plant attributes to enhance biological control. Biological Control 17: 35-49.

De Moraes, C. M., Lewis, W. J., Pare, P. W., Alborn, H. T. \& Tumlinson, J. H. (1998). Herbivore-infested plants selectively attract parasitoids. Nature 393: 570-573.

De Moraes, C. M., Mescher, M. C. \& Tumlinson, J. H. (2001). Caterpillar-induced nocturnal plant volatiles repel nonspecific females. Nature 410: 577-580.

Degenhardt, J. \& Gershenzon, J. (2000). Demonstration and characterization of $(E)$-nerolidol synthase from maize: a herbivore-inducible terpene synthase participating in (3E)-4,8-dimethyl-1,3,7-nonatriene biosynthesis. Planta 210: $815-822$.

Del-Claro, K. \& Oliveira, P. S. (1993). Ant-Homoptera interaction: do alternative sugar sources distract tending ants? Oikos 68: 202-206. 
Dicke, M. (1986). Volatile spider-mite pheromone and host-plant kairomone, involved in spaced-out gregariousness in the spider-mite Tetranychus urticae. Physiological Entomology 11: 251-262.

(1994). Local and systemic production of volatile herbivore-induced terpenoids: their role in plant-carnivore mutualism. Journal of Plant Physiology 143: 465-472.

(1999). Are herbivore-induced plant volatiles reliable indicators of herbivore identity to foraging carnivorous arthropods? Entomologia Experimentalis et Applicata 91: $131-142$.

Dicke, M. \& Dijkman, H. (1992). Induced defense in detached uninfested plant-leaves: effects on behavior of herbivores and their predators. Oecologia 91: 554-560.

Dicke, M. \& Groeneveld, A. (1986). Hierarchical structure in kairomone preference of the predatory mite Amblyseius potentillae: dietary component indispensable for diapause induction affects prey location behavior. Ecological Entomology 11: 131-138.

Dicke, M. \& Sabelis, M. W. (1988). How plants obtain predatory mites as bodyguards. Netherlands Journal of Zoology 38: 148-165.

Dicke, M., Sabelis, M. W., Takabayashi, J., Bruin, J. \& Posthumus, M. A. (1990a). Plant strategies of manipulating predator-prey interactions through allelochemicals: prospects for application in pest-control. Journal of Chemical Ecology 16: 3091-3118.

Dicke, M., Vanbeek, T. A., Posthumus, M. A., Bendom, N., Vanbokhoven, H. \& Degroot, A. E. (1990b). Isolation and identification of volatile kairomone that affects acarine predator-prey interactions: involvement of host plant in its production. Journal of Chemical Ecology 16: 381-396.

Dicke, M., Vanbaarlen, P., Wessels, R. \& Dijkman, H. (1993). Herbivory induces systemic production of plant volatiles that attract predators of the herbivore - extraction of endogenous elicitor. Journal of Chemical Ecology 19: 581-599.

Dicke, M., Gols, R., Ludeking, D. \& Posthumus, M. A. (1999). Jasmonic acid and herbivory differentially induce carnivore-attracting plant volatiles in lima bean plants. Journal of Chemical Ecology 25: 1907-1922.

Dicke, M., Schutte, C. \& Dijkman, H. (2000). Change in behavioral response to herbivore-induced plant volatiles in a predatory mite population. Journal of Chemical Ecology 26: 1497-1514.

Dicke, M., Van Poecke, R. M. P. \& De Boer, J. G. (2003). Inducible indirect defence of plants: from mechanism to ecological functions. Basic and Applied Ecology 4: 27-42.

Doherty, H. M., Selvendran, R. R. \& Bowles, D. J. (1988). The wound response of tomato plants can be inhibited by aspirin and related hydroxybenzoic acids. Physiological and Molecular Plant Pathology 33: 377-384.

Dolch, R. \& Tscharntke, T. (2000). Defoliation of alders (Alnus glutinosa) affects herbivory by leaf beetles on undamaged neighbours. Oecologia 125: 504-511.

Domek, J. M. \& Johnson, D. T. (1988). Demonstration of semiochemically induced aggregation in the green june beetle, Cotinis nitida (L) (Coleoptera, Scarabaeidae). Environmental Entomology 17: 147-149.

Donath, J. \& Boland, W. (1994). Biosynthesis of acyclic homoterpenes in higher-plants parallels steroid-hormone metabolism. Journal of Plant Physiology 143: 473-478.

Drukker, B., Scutareanu, P. \& Sabelis, M. W. (1995). Do anthocorid predators respond to synomones from Psylla-infested pear trees under field conditions. Entomologia Experimentalis et Applicata 77: 193-203.

Du, Y. J., Poppy, G. M. \& Powell, W. (1996). Relative importance of semiochemicals from first and second trophic levels in host foraging behavior of Aphidius ervi. Journal of Chemical Ecology 22: 1591-1605. 
Du, Y. J., Poppy, G. M., Powell, W., Pickett, J. A., Wadhams, L. J. \& Woodcock, C. M. (1998). Identification of semiochemicals released during aphid feeding that attract parasitoid Aphidius ervi. Journal of Chemical Ecology 24: 1355-1368.

Eben, A., Benrey, B., Sivinski, J. \& Aluja, M. (2000). Host species and host plant effects on preference and performance of Diachasmimorpha longicaudata (Hymenoptera: Braconidae). Environmental Entomology 29: 87-94.

Ecker, J. R. \& Davis, R. W. (1987). Plant defense genes are regulated by ethylene. Proceedings of the National Academy of Sciences, USA 84: 5202-5206.

Elzen, G. W., Williams, H. J. \& Vinson, S. B. (1984). Isolation and identification of cotton synomones mediating searching behavior by parasitoid Campoletis sonorensis. Journal of Chemical Ecology 10: 1251-1264.

Elzen, G. W., Williams, H. J., Bell, A. A., Stipanovic, R. D. \& Vinson, S. B. (1985). Quantification of volatile terpenes of glanded and glandless Gossypium hirsutum L. cultivars and lines by gas-chromatography. Journal of Agricultural and Food Chemistry 33: 1079-1082.

Engel, V., Fischer, M. K., Wackers, F. L. \& Volkl, W. (2001). Interactions between extrafloral nectaries, aphids and ants: are there competition effects between plant and homopteran sugar sources? Oecologia 129: 577-584.

Engelberth, J., Koch, T., Kuhnemann, F. \& Boland, W. (2000). Channel-forming peptaibols are potent elicitors of plant secondary metabolism and tendril coiling. Angewandte Chemie: International Edition 39: 1860-1862.

Engelberth, J., Koch, T., Schuler, G., Bachmann, N., Rechtenbach, J. \& Boland, W. (2001). Ion channel-forming alamethicin is a potent elicitor of volatile biosynthesis and tendril coiling. Cross talk between jasmonate and salicylate signaling in lima bean. Plant Physiology 125: 369-377.

Enyedi, A. J., Yalpani, N., Silverman, P. \& Raskin, I. (1992). Localization, conjugation, and function of salicylic-acid in tobacco during the hypersensitive reaction to tobacco mosaic-virus. Proceedings of the National Academy of Sciences, USA 89: 2480-2484.

Faegri, K. \& van der Pijl, L. (1971). The Principles of Pollination Ecology. Oxford: Pergamon Press.

Faeth, S. H. (1994). Induced plant responses: effects on parasitoids and other natural enemies of phytophagous insects. In Parasitoid Community Ecology, eds. B. A. Hawkins \& W. Sheehan, pp. 245-260. Oxford: Oxford University Press.

Farmer, E. E. (2001). Surface-to-air signals. Nature 411: 854-856.

Farmer, E. E. \& Ryan, C. A. (1990). Interplant communication: airborne methyl jasmonate induces synthesis of proteinase-inhibitors in plant-leaves. Proceedings of the National Academy of Sciences, USA 87: 7713-7716.

Farmer, E. E., Johnson, R. R. \& Ryan, C. A. (1992). Regulation of expression of proteinase-inhibitor genes by methyl jasmonate and jasmonic acid. Plant Physiology 98: 995-1002.

Farmer, E. E., Weber, H. \& Vollenweider, S. (1998). Fatty acid signaling in Arabidopsis. Planta 206: 167-174.

Felton, G. W. \& Eichenseer, H. (2000). Herbivore saliva and its effects on plant defense against herbivores and pathogens. In Induced Plant Defenses Against Pathogens and Herbivores: Biochemistry, Ecology, and Agriculture, eds. A. A. Agrawal, S. Tuzan \& E. Bent, pp. 19-36. St Paul, MO: APS Press.

Finidori-Logli, V., Bagneres, A. G. \& Clement, J. L. (1996). Role of plant volatiles in the search for a host by parasitoid Diglyphus isaea (Hymenoptera: Eulophidae). Journal of Chemical Ecology 22: 541-558. 
Fisher, B. L., Sternberg, L. D. L. \& Price, D. (1990). Variation in the use of orchid extrafloral nectar by ants. Oecologia 83: 263-266.

Flint, H. M., Salter, S. S. \& Walters, S. (1979). Caryophyllene: an attractant for the green lacewing. Environmental Entomology 8: 1123-1125.

Fowler, S. V. \& Lawton, J. H. (1985). Rapidly induced defenses and talking trees: the devil's advocate position. American Naturalist 126: 181-195.

Frey, M., Chomet, P., Glawischnig, E. et al. (1997). Analysis of a chemical plant defense mechanism in grasses. Science 277: 696-699.

Frey, M., Stettner, C., Pare, P. W., Schmelz, E. A., Tumlinson, J. H. \& Gierl, A. (2000). An herbivore elicitor activates the gene for indole emission in maize. Proceedings of the National Academy of Sciences, USA 97: 14801-14806.

Frey-Wyssling, A. (1955). The phloem supply to the nectaries. Acta Botanica Neerlandica 4: 358-369.

Fritzsche Hoballah, M. E. F. \& Turlings, T. C. J. (2001). Experimental evidence that plants under caterpillar attack may benefit from attracting parasitoids. Evolutionary Ecology Research 3: 553-565.

Fritzsche Hoballah, M. E. F., Tamo, C. \& Turlings, T. C. J. (2002). Differential attractiveness of induced odors emitted by eight maize varieties for the parasitoid Cotesia marginiventris: is quality or quantity important? Journal of Chemical Ecology 28: 951-968.

Fujiwara, C., Takabayashi, J. \& Yano, S. (2000). Effects of host-food plant species on parasitization rates of Mythimna separata (Lepidoptera: Noctuidae) by a parasitoid, Cotesia kariyai (Hymenoptera: Braconidae). Applied Entomology and Zoology 35: 131-136.

Geervliet, J. B. F., Vet, L. E. M. \& Dicke, M. (1994). Volatiles from damaged plants as major cues in long-range host-searching by the specialist parasitoid Cotesia rubecula. Entomologia Experimentalis et Applicata 73: 289-297.

(1996). Innate responses of the parasitoids Cotesia glomerata and C. rubecula (Hymenoptera: Braconidae) to volatiles from different plant-herbivore complexes. Journal of Insect Behavior 9: 525-538.

Gómez, J. M. \& Zamora, R. (1994). Top-down effects in a tritrophic system: parasitoids enhance plant fitness. Ecology 75: 1023-1030.

Gorlach, J., Volrath, S., Knaufbeiter, G. et al. (1996). Benzothiadiazole, a novel class of inducers of systemic acquired resistance, activates gene expression and disease resistance in wheat. Plant Cell 8: 629-643.

Gouinguené, S. (2000). Specificity and variability in induced volatile signalling in maize plants, University of Neuchâtel, the Netherlands.

Gouinguené, S., Degen, T. \& Turlings, T. C. J. (2001). Variability in herbivore-induced odour emissions among maize cultivars and their wild ancestors (teosinte). Chemoecology 11: 9-16.

Hagen, K. S. (1986). Ecosystem analysis: plant cultivar (HPR), entomophagous species and food supplements. In Interactions of Plant Resistance and Parasitoids and Predators of Insects, eds. D. J. Boethel \& R. D. Eikenbary, pp. 153-197. New York: John Wiley and Sons.

Halitschke, R., Schittko, U., Pohnert, G., Boland, W. \& Baldwin, I. T. (2001). Molecular interactions between the specialist herbivore Manduca sexta (Lepidoptera, Sphingidae) and its natural host Nicotiana attenuata. III. Fatty acidamino acid conjugates in herbivore oral secretions are necessary and sufficient for herbivore-specific plant responses. Plant Physiology 125: 711-717. 
Harari, A. R., Benyakir, D. \& Rosen, D. (1994). Mechanism of aggregation behavior in Maladera matrida Argaman (Coleoptera, Scarabaeidae). Journal of Chemical Ecology 20: 361-371.

Hare, J. D. (2002). Plant genetic variation in tritrophic interactions. In Multitrophic Level Interactions, eds. T. Tscharntke \& B. A. Hawkins, pp. 8-43. Cambridge: Cambridge University Press.

Harrewijn, P., Minks, A. K. \& Mollema, C. (1995). Evolution of plant volatile production in insect-plant relationships. Chemoecology 5/6: 55-73.

Harrington, E. A. \& Barbosa, P. (1978). Host habitat influences on oviposition by Parasetigena silvestris (R-D) (Diptera-Tachinidae), a larval parasite of gypsy moth (Lepidoptera-Lymantriidae). Environmental Entomology 7: 466-468.

Haskins, C. P. \& Haskins, E. F. (1950). Notes on the biology and social behavior of the archaic ponerine ants of the genera Myrmeca and Promyrmeca. Annals of the Entomological Society of America 43: 461-491.

Hatcher, P. E. (1995). Three-way interactions between plant-pathogenic fungi, herbivorous insects and their host plants. Biological Reviews of the Cambridge Philosophical Society 70: 639-694.

Hatcher, P. E. \& Paul, N. D. (2000). Beetle grazing reduces natural infection of Rumex obtusifolius by fungal pathogens. New Phytologist 146: 325-333.

Hatcher, P. E., Paul, N. D., Ayres, P. G. \& Whittaker, J. B. (1994a). The effect of an insect herbivore and a rust fungus individually, and combined in sequence, on the growth of 2 Rumex species. New Phytologist 128: 71-78.

(1994b). Interactions between Rumex spp., herbivores and a rust fungus: Gastrophysa viridula grazing reduces subsequent infection by Uromyces rumicis. Functional Ecology 8: 265-272.

Hatcher, P. E., Ayres, P. G. \& Paul, N. D. (1995). The effect of natural and simulated insect herbivory, and leaf age, on the process of infection of Rumex crispus L. and $R$. obtusifolius L. by Uromyces rumicis (Schum) Wint. New Phytologist 130: 239-249.

Haukioja, E., Suomela, J. \& Neuvonen, S. (1985). Long-term inducible resistance in birch foliage: triggering cues and efficacy on a defoliator. Oecologia 65: 363-369.

Heil, M., Fiala, B., Baumann, B. \& Linsenmair, K. E. (2000). Temporal, spatial and biotic variations in extrafloral nectar secretion by Macaranga tanarius. Functional Ecology 14: 749-757.

Heil, M., Koch, T., Hilpert, A., Fiala, B., Boland, W. \& Linsenmair, K. E. (2001). Extrafloral nectar production of the ant-associated plant, Macaranga tanarius, is an induced, indirect, defensive response elicited by jasmonic acid. Proceedings of the National Academy of Sciences, USA 98: 1083-1088.

Hilbeck, A., Baumgartner, M., Fried, P. M. \& Bigler, F. (1998). Effects of transgenic Bacillus thuringiensis corn-fed prey on mortality and development time of immature Chrysoperla carnea (Neuroptera: Chrysopidae). Environmental Entomology 27: 480-487.

Hölldobler, B. \& Wilson, E. O. (1990). The Ants. Cambridge, MA: Harvard University Press.

Hopke, J., Donath, J., Blechert, S. \& Boland, W. (1994). Herbivore-induced volatiles: the emission of acyclic homoterpenes from leaves of phaseolus-lunatus and Zea mays can be triggered by a beta-glucosidase and jasmonic acid. Febs Letters 352: 146-150.

Horvitz, C. C. \& Schemske, D. W. (1986). Seed dispersal of a neotropical myrmecochore: variation in removal rates and dispersal distance. Biotropica 18: 319-323.

Ichihara, A., Shiraishi, K., Sato, H. et al. (1977). Structure of coronatine. Journal of the American Chemical Society 99: 636-637. 
Inouye, D. W. \& Taylor, O. R. (1979). Temperate region plant-ant-seed predator system: consequences of extra floral nectar secretion by Helianthella quinquenervis. Ecology 60: $1-7$.

Janssen, A., Pallini, A., Venzon, M. \& Sabelis, M. W. (1998). Behaviour and indirect interactions in food webs of plant-inhabiting arthropods. Experimental and Applied Acarology 22: 497-521.

Janzen, D. H. (1966). Coevolution of mutualism between ants and acacias in Central America. Evolution 20: 249-275.

Jervis, M. A. \& Kidd, N. A. C. (1996). Phytophagy. In Insect Natural Enemies: Practical Approaches in Their Study and Avaluation, eds. M. A. Jervis \& N. A. C. Kidd, pp. 375-394. London: Chapman \& Hall.

Jervis, M. A., Kidd, N. A. C., Fitton, M. G., Huddleston, T. \& Dawah, H. A. (1993). Flower-visiting by hymenopteran parasitoids. Journal of Natural History 27: 67-105.

Jolivet, P. (1998). Myrmecophily and Ant-Plants. Boca Raton, FL: CRC Press.

Josens, R. B., Farina, W. M. \& Roces, F. (1998). Nectar feeding by the ant Camponotus mus: intake rate and crop filling as a function of sucrose concentration. Journal of Insect Physiology 44: 579-585.

Kahl, J., Siemens, D. H., Aerts, R. J. et al. (2000). Herbivore-induced ethylene suppresses a direct defense but not a putative indirect defense against an adapted herbivore. Planta 210: 336-342.

Kalberer, N. M., Turlings, T. C. J. \& Rahier, M. (2001). Attraction of a leaf beetle (Oreina cacaliae) to damaged host plants. Journal of Chemical Ecology 27: 647-661.

Karban, R. \& Baldwin, I. T. (1997). Induced Responses to Herbivory. Chicago, IL: University Press of Chicago.

Karban, R. \& Kuc, J. (1999). Induced resistance against pathogens and herbivore: an overview. In Induced Plant Defenses Against Pathogens and Herbivores, eds. A. A. Agrawal, S. Tuzun \& E. Bent, pp. 1-15. St Paul, MO: APS Press.

Karban, R., Agrawal, A. A. \& Mangel, M. (1997). The benefits of induced defenses against herbivores. Ecology 78: 1351-1355.

Karban, R., Baldwin, I. T., Baxter, K. J., Laue, G. \& Felton, G. W. (2000). Communication between plants: induced resistance in wild tobacco plants following clipping of neighboring sagebrush. Oecologia 125: 66-71.

Kessler, A. \& Baldwin, I. T. (2001). Defensive function of herbivore-induced plant volatile emissions in nature. Science 291: 2141-2144.

Kessmann, H., Staub, T., Hofmann, C. et al. (1994). Induction of systemic acquired disease resistance in plants by chemicals. Annual Review of Phytopathology 32: 439-459.

Knoester, M., van Loon, L. C., van den Heuvel, J., Hennig, J., Bol, J. F. \& Linthorst, H. J. M. (1998). Ethylene-insensitive tobacco lacks nonhost resistance against soil-borne fungi. Proceedings of the National Academy of Sciences, USA 95: 1933-1937.

Koch, T., Krumm, T., Jung, V., Engelberth, J. \& Boland, W. (1999). Differential induction of plant volatile biosynthesis in the lima bean by early and late intermediates of the octadecanoid-signaling pathway. Plant Physiology 121: 153-162.

Koptur, S. (1979). Facultative mutualism between weedy vetches bearing extrafloral nectaries and weedy ants in California. American Journal of Botany 66: 1016-1020.

(1989). Is extrafloral nectar production an inducible defence? In Evolutionary Ecology of Plants, eds. J. Bock \& Y. Linhart, pp. 323-339. Boulder, CO: Westview Press.

(1992). Extrafloral nectary-mediated interactions between insects and plants. In Insect-Plant Interactions, vol. IV, ed. E. A. Bernays, pp. 81-129. Boca Raton, FL: CRC Press. 
(1994). Floral and extrafloral nectars of Costa Rican Inga trees: a comparison of their constituents and composition. Biotropica 26: 276-284.

Koptur, S. \& Lawton, J. H. (1988). Interactions among vetches bearing extrafloral nectaries, their biotic protective agents, and herbivores. Ecology 69: 278-283.

Koptur, S., Rico-Gray, V. \& Palacios-Rios, M. (1998). Ant protection of the nectaried fern Polypodium plebeium in central Mexico. American Journal of Botany 85: 736-739.

Krips, O. E., Willems, P. E. L., Gols, R., Posthumus, M. A., Gort, G. \& Dicke, M. (2001). Comparison of cultivars of ornamental crop Gerbera jamesonii on production of spider mite-induced volatiles, and their attractiveness to the predator Phytoseiulus persimilis. Journal of Chemical Ecology 27: 1355-1372.

Krivan, V. \& Sirot, E. (1997). Searching for food or hosts. The influence of parasitoids behavior on host-parasitoid dynamics. Theoretical Population Biology 51: 201-209.

Landolt, P. J. (1993). Effects of host plant leaf damage on cabbage-looper moth attraction and oviposition. Entomologia Experimentalis et Applicata 67: 79-85.

Landolt, P. J., Tumlinson, J. H. \& Alborn, D. H. (1999). Attraction of Colorado potato beetle (Coleoptera: Chrysomelidae) to damaged and chemically induced potato plants. Environmental Entomology 28: 973-978.

Lanza, J. (1988). Ant preferences for Passiflora nectar mimics that contain amino-acids. Biotropica 20: 341-344.

Leahy, T. C. \& Andow, D. A. (1994). Egg weight, fecundity, and longevity are increased by adult feeding in Ostrinia nubilalis (Lepidoptera, Pyralidae). Annals of the Entomological Society of America 87: 342-349.

Leatemia, J. A., Laing, J. E. \& Corrigan, J. E. (1995). Effects of adult nutrition on longevity, fecundity, and offspring sex-ratio of Trichogramma minutum Riley (Hymenoptera, Trichogrammatidae). Canadian Entomologist 127: 245-254.

Letourneau, D. K. (1990). Code of ant-plant mutualism broken by parasite. Science 248: 215-217.

Lewis, W. J., Stapel, J. O., Cortesero, A. M. \& Takasu, K. (1998). Understanding how parasitoids balance food and host needs: importance to biological control. Biological Control 11: 175-183.

Lingren, P. D. \& Lukefahr, M. J. (1977). Effects of nectariless cotton on caged populations of Campoletis sonorensis (Hymenoptera-Ichneumonidae). Environmental Entomology 6: 586-588.

Loch, A. D. \& Walter, G. H. (1999). Multiple host use by egg parasitoid Trissolcus basalis (Wollaston) in a soyabean agricultural system: biological control and environmental implications. Agricultural and Forest Entomology 1: 271-280.

Loke, W. H., Ashley, T. R. \& Sailer, R. I. (1983). Influence of fall armyworm, Spodoptera frugiperda (Lepidoptera, Noctuidae) larvae and corn plant-damage on host finding in Apanteles marginiventris (Hymenoptera, Braconidae). Environmental Entomology 12: 911-915.

Lou, Y. \& Cheng, J. (1996). Behavioral responses of Anagrus nilaparvatae Pang et Wang to the volatiles of rice varieties. Entomological Journal of East China 5: 60-64.

Loughrin, J. H., Manukian, A., Heath, R. R., Turlings, T. C. J. \& Tumlinson, J. H. (1994). Diurnal cycle of emission of induced volatile terpenoids herbivore-injured cotton plants. Proceedings of the National Academy of Sciences, USA 91: 11836-11840.

Loughrin, J. H., Manukian, A., Heath, R. R. \& Tumlinson, J. H. (1995a). Volatiles emitted by different cotton varieties damaged by feeding beet armyworm larvae. Journal of Chemical Ecology 21: 1217-1227. 
Loughrin, J. H., Potter, D. A. \& Hamiltonkemp, T. R. (1995b). Volative compounds induced by herbivory act as aggregation kairomones for the japanese-beetle (Popillia japonica Newman). Journal of Chemical Ecology 21: 1457-1467.

Maeda, T., Takabayashi, J., Yano, S. \& Takafuji, A. (1999). Response of the predatory mite, Amblyseius womersleyi (Acari: Phytoseiidae), toward herbivore-induced plant volatiles: variation in response between two local populations. Applied Entomology and Zoology 34: 449-454.

Margolies, D. C., Sabelis, M. W. \& Boyer, J. E. (1997). Response of a phytoseiid predator to herbivore-induced plant volatiles: selection on attraction and effect on prey exploitation. Journal of Insect Behavior 10: 695-709.

Markin, G. P. (1970). Food distribution within laboratory colonies of argentine ant, Iridomyrmex humilis (Mayr). Insectes Sociaux 17: 127-158.

Mattiacci, L., Dicke, M. \& Posthumus, M. A. (1994). Induction of parasitoid attracting synomone in brussels-sprouts plants by feeding of Pieris brassicae larvae: role of mechanical damage and herbivore elicitor. Journal of Chemical Ecology 20: 2229-2247.

(1995). Beta-glucosidase: an elicitor of herbivore-induced plant odor that attracts host-searching parasitic wasps. Proceedings of the National Academy of Sciences, USA 92: 2036-2040.

Mattoo, A. K. \& Suttle, J. C. (1991). The Plant Hormone Ethylene. Boca Raton, FL: CRC Press.

McCall, P. J., Turlings, T. C. J., Lewis, W. J. \& Tumlinson, J. H. (1993). Role of plant volatiles in host location by the specialist parasitoid Microplitis croceipes Cresson (Braconidae, Hymenoptera). Journal of Insect Behavior 6: 625-639.

McCall, P. J., Turlings, T. C. J., Loughrin, J., Proveaux, A. T. \& Tumlinson, J. H. (1994). Herbivore-induced volatile emissions from cotton (Gossypium hirsutum L) seedlings. Journal of Chemical Ecology 20: 3039-3050.

McEwen, P. K. \& Liber, H. (1995). The effect of adult nutrition on the fecundity and longevity of the alive moth Prays oleae (Bern). Journal of Applied Entomology (Zeitschrift für Angewandte Entomologie) 119: 291-294.

Meiners, T. \& Hilker, M. (1997). Host location in Oomyzus gallerucae (Hymenoptera: Eulophidae), an egg parasitoid of the elm leaf beetle Xanthogaleruca luteola (Coleoptera: Chrysomelidae). Oecologia 112: 87-93.

(2000). Induction of plant synomones by oviposition of a phytophagous insect. Journal of Chemical Ecology 26: 221-232.

Meiners, T., Westerhaus, C. \& Hilker, M. (2000). Specificity of chemical cues used by a specialist egg parasitoid during host location. Entomologia Experimentalis et Applicata 95: 151-159.

Milewski, A. V. \& Bond, W. J. (1982). Convergence of myrmercochory in mediterranean Australia and South Africa. In Ant-Plant Interactions in Australia, ed. R. C. Buckley, pp. 89-98. The Hague: Junk.

Mohyuddin, A. I., Inayatullah, C. \& King, E. G. (1981). Host selection and strain occurence in Apalantes flavipes (Cameron) (Hymenoptera: Braconidae) and its bearing on biological control of graminaceous stem-borers (Lepidoptera: Pyralidae). Bulletin of Entomological Research 71: 575-581.

Monteith, L. G. (1955). Host preferences of Drino bohemica Messn. (Diptera: Tachinidae) with particular reference to olfactory responses. Canadian Entomologist 87: 509-530.

Moran, P. (1998). Plant-mediated interactions between insects and a fungal plant pathogen and the role of plant chemical responses to infection. Oecologia 115: 523-530. 
Nordlund, D. A. \& Sauls, C. E. (1981). Kairomones and their use for management of entomophagous insects. 11. Effect of host plants on kairomonal activity of frass from Heliothis zea (Lepidoptera, Noctuidae) larvae for the parasitoid Microplitis croceipes (Hymenoptera, Braconidae). Journal of Chemical Ecology 7: 1057-1061.

Nordlund, D. A., Lewis, L. C. \& Altieri, M. A. (1988). Influences of plant-produced allelochemicals on the host/prey selection behavior of entomophagous insects. In Novel Aspects of Insect-Plant Interactions, eds. P. Barbosa \& D. Letourneau, pp. 65-90. New York: John Wiley and Sons.

O'Dowd, D. J. (1979). Foliar nectar production and ant activity on a neotropical tree, Ochroma pyramidale. Oecologia 43: 233-248.

O’Dowd, D. J. \& Catchpole, E. A. (1983). Ants and extrafloral nectaries: no evidence for plant-protection in Helichrysum spp. ant interactions. Oecologia 59: 191-200.

Oliveira, P. S. (1997). The ecological function of extrafloral nectaries: herbivore deterrence by visiting ants and reproductive output in Caryocar brasiliense (Caryocaraceae). Functional Ecology 11: 323-330.

Orr, D. B. \& Landis, D. L. (1997). Oviposition of European corn borer (Lepidoptera: Pyralidae) and impact of natural enemy populations in transgenic versus isogenic corn. Journal of Economic Entomology 90: 905-909.

Ozawa, R., Arimura, G., Takabayashi, J., Shimoda, T. \& Nishioka, T. (2000). Involvement of jasmonate- and salicylate-related signaling pathways for the production of specific herbivore-induced volatiles in plants. Plant and Cell Physiology 41: 391-398.

Padgette, S. R., Re, D. B., Barry, G. F. et al. (1994). New weed control opportunities: development of soybeans with a Roundup Ready ${ }^{\mathrm{TM}}$ gene. In Herbicide-resistant Crops: Agricultural, Economics, Environmental, Regulatory, and Technologycal Aspects, ed. S. O. Duke. Boca Raton, FL: CRC Press.

Pallini, A., Janssen, A. \& Sabelis, M. W. (1997). Odour-mediated responses of phytophagous mites to conspecific and heterospecific competitors. Oecologia 110: 179-185.

Paré, P. W. \& Tumlinson, J. H. (1997). De novo biosynthesis of volatiles induced by insect herbivory in cotton plants. Plant Physiology 114: 1161-1167.

(1999). Plant volatiles as a defense against insect herbivores. Plant Physiology 121: 325-331.

Paré, P. W., Alborn, H. T. \& Tumlinson, J. H. (1998). Concerted biosynthesis of an insect elicitor of plant volatiles. Proceedings of the National Academy of Sciences, USA 95: 13971-13975.

Pascal, L. \& Belin-Depoux, M. (1991). La correlation entre les rythmes biologiques de l'association plante-fourmis: les cas des nectaries extra-floraux de Malpighiaceae americaines. Comptes Rendus Hebdomadaires des Séances de l'Académie des Sciences, Paris series III, 312: 49-54.

Passera, L., Lachaud, J. P. \& Gomel, L. (1994). Individual food source fidelity in the neotropical ponerine ant Ectatomma ruidum Roger (Hymenoptera-Formicidae). Ethology Ecology and Evolution 6: 13-21.

Pemberton, P. W. (1998). The occurence and abundance of plants with extrafloral nectaries, the basis for antiherbivore defensive mutualisms, along a latitudinal gradient in east Asia. Journal of Biogeography 25: 661-668.

Pemberton, R. W. \& Lee, J. H. (1996). The influence of extrafloral nectaries on parasitism of an insect herbivore. American Journal of Botany 83: 1187-1194.

Peng, C. W. \& Weiss, M. J. (1992). Evidence of an aggregation pheromone in the flea beetle, Phyllotreta cruciferae (Goeze) (Coleoptera, Chrysomelidae). Journal of Chemical Ecology 18: 875-884. 
Pettersson, E. M. (2001). Volatiles from potential hosts of Rhopalicus tutela a bark beetle parasitoid. Journal of Chemical Ecology 27: 2219-2231.

Pettersson, E. M., Birgersson, G. \& Witzgall, P. (2001). Synthetic attractants for the bark beetle parasitoid Coeloides bostrichorum Giraud (Hymenoptera: Braconidae). Naturwissenschaften 88: 88-91.

Picard, F. \& Rabaud, E. (1914). Sur le parasitisme externe des Braconidae. Bulletin de la Société Entomologique de France 83: 266-269.

Piel, J., Atzorn, R., Gabler, R., Kuhnemann, F. \& Boland, W. (1997). Cellulysin from the plant parasitic fungus Trichoderma viride elicits volatile biosynthesis in higher plants via the octadecanoid signalling cascade. Febs Letters 416: 143-148.

Pilcher, C. D., Obrycki, J. J., Rice, M. E. \& Lewis, L. C. (1997). Preimaginal development, survival, and field abundance of insect predators on transgenic Bacillus thuringiensis corn. Environmental Entomology 26: 446-454.

Pohnert, G., Jung, V., Haukioja, E., Lempa, K. \& Boland, W. (1999). New fatty acid amides from regurgitant of lepidopteran (Noctuidae, Geometridae) caterpillars. Tetrahedron 55: 11275-11280.

Porter, S. D. (1989). Effects of diet on the growth of laboratory fire ant colonies (Hymenoptera, Formicidae). Journal of the Kansas Entomological Society 62: 288-291.

Potting, R. P. J., Vet, L. E. M. \& Dicke, M. (1995). Host microhabitat location by stem-borer parasitoid Cotesia flavipes: the role of herbivore volatiles and locally and systemically induced plant volatiles. Journal of Chemical Ecology 21: 525-539.

Powell, W., Pennacchio, F., Poppy, G. M. \& Tremblay, E. (1998). Strategies involved in the location of hosts by the parasitoid Aphidius ervi Haliday (Hymenoptera: Braconidae: Aphidiinae). Biological Control 11: 104-112.

Price, P. W., Bouton, C. E., Gross, P., Mcpheron, B. A., Thompson, J. N. \& Weis, A. E. (1980). Interactions among 3 trophic levels: influence of plants on interactions between insect herbivores and natural enemies. Annual Review of Ecology and Systematics 11: 41-65.

Pyke, G. H. (1991). What does it cost a plant to produce floral nectar? Nature 350: 58-59.

Ramachandran, R. \& Norris, D. M. (1991). Volatiles mediating plant-herbivore-natural enemy interactions: electroantennogram responses of soybean looper, Pseudoplusia includens, and a parasitoid, Microplitis demolitor, to green leaf volatiles. Journal of Chemical Ecology 17: 1665-1690.

Rapusas, H. R., Bottrell, D. G. \& Coll, M. (1996). Intraspecific variation in chemical attraction of rice to insect predators. Biological Control 6: 394-400.

Retana, J., Bosch, J., Alsina, A. \& Cerdá, X. (1987). Foraging ecology of the nectarivorous ant Camponotus foreli (Hymenoptera, Formicidae) in a savanna-like grassland. Misselània Zoològica 11: 187-193.

Reymond, P. \& Farmer, E. E. (1998). Jasmonate and salicylate as global signals for defense gene expression. Current Opinion in Plant Biology 1: 404-411.

Reymond, P., Weber, H., Damond, M. \& Farmer, E. E. (2000). Differential gene expression in response to mechanical wounding and insect feeding in Arabidopsis. Plant Cell 12: 707-719.

Rhoades, D. F. (1979). Evolution of plant chemical defense against herbivores. In Herbivores: Their Interaction with Secondary Plant Metabolites, eds. G. A. Rosenthal \& D. H. Janzen, pp. 4-54. New York: Academic Press.

(1983). Responses of alder and willow to attack by tent caterpillars and webworms: evidence for pheromonal sensitivity of willows. In Plant Resistance to Insects, ed. P. A. Hedin, pp. 55-68. Washington, DC: American Chemical Society. 
(1985). Pheromonal communication between plants. In Chemically Mediated Interactions Between Plants and Other Organisms. Recent Advances in Phytochemistry, eds. G. A. Cooper-Driver, T. Swain \& E. C. Conn, pp. 195-218. New York: Plenum Press.

Rickson, F. R. (1977). Progressive loss of ant-related traits of Cecropia peltata on selected caribbean islands. American Journal of Botany 64: 585-592.

(1980). Developmental anatomy and ultrastructure of the ant-food bodies (beccariian bodies) of Macaranga triloba and M. Hypoleuca (Euphorbiaceae). American Journal of Botany 67: 285-292.

Rico-Gray, V. \& Thien, L. B. (1989). Effect of different ant species on reproductive fitness of Schomburgkia tibicinis (Orchidaceae). Oecologia 81: 487-489.

Rico-Gray, V., Garcia-Franco, J. G., Palacios-Rios, M., Diaz-Castelazo, C., Parra-Tabla, V. \& Navarro, J. A. (1998). Geographical and seasonal variation in the richness of ant-plant interactions in Mexico. Biotropica 30: 190-200.

Risch, S. J. \& Rickson, F. R. (1981). Mutualism in which ants must be present before plants produce food bodies. Nature 291: 149-150.

Robinson, D., Price, R. G. \& Dance, N. (1967). Separation and properties of beta-galactosidase, beta-glucosidase, beta-glucuronidase and $\mathrm{N}$-acetyl-beta-glucosaminidase from rat kidney. Biochemical Journal 102: 525.

Rodriguez-Saona, C., Crafts-Brander, S. J., Paré, P. W. \& Henneberry, T. J. (2001). Exogenous methyl jasmonate induces volatile emissions in cotton plants. Journal of Chemical Ecology 27: 679-695.

Rogers, C. E. (1985). Extrafloral nectar: entomological implications. Bulletin of the Entomological Society of America 31: 15-20.

Romeis, J. \& Wäckers, F. L. (2000). Feeding responses by female Pieris brassicae butterflies to carbohydrates and amino acids. Physiological Entomology 25: 247-253.

(2002). Nutritional suitability of individual carbohydrates and amino acids for adult Pieris brassicae. Physiological Entomology 27: 148-156.

Röse, U. S. R., Manukian, A., Heath, R. R. \& Tumlinson, J. H. (1996). Volatile semiochemicals released from undamaged cotton leaves: a systemic response of living plants to caterpillar damage. Plant Physiology 111: 487-495.

Rostàs, M., Simon, M. \& Hilker, M. (2003). Ecological cross-effects of induced plant responses towards herbivores and phytopathogenic fungi. Basic and Applied Ecology 4: 43-62.

Roth, J. P., King, E. G. \& Thompson, A. C. (1978). Host location by the tachinid Lixophaga diatreae. Environmental Entomology 7: 794-798.

Ruhren, S. \& Handel, S. N. (1999). Jumping spiders (Salticidae) enhance the seed production of a plant with extrafloral nectaries. Oecologia 119: 227-230.

Ryals, J. A., Neuenschwander, U. H., Willits, M. G., Molina, A., Steiner, H. Y. \& Hunt, M. D. (1996). Systemic acquired resistance. Plant Cell 8: 1809-1819.

Sabelis, M. W. \& van de baan, H. E. (1983). Location of distant spider-mite colonies by phytoseiid predators: demonstration of specific kairomones emitted by Tetranychus urticae and Panonychus ulmi. Entomologia Experimentalis et Applicata 33: 303-314.

Sabelis, M. W., van Baalen, M., Bakker, F. M. et al. (1999). The evolution of direct and indirect plant defence against herbivorous arthropods. In Herbivores: Between Plants and Predators, eds. H. Olf, V. K. Brown \& R. H. Drent, pp. 109-166. Oxford: Blackwell.

Salt, G. (1958). Parasite behaviour and the control of insect pests. Endeavour 17: 145-148.

Sano, K., Amemura, A. \& Harada, T. (1975). Purification and properties of a beta-1,6-glucosidase from Flavobacterium. Biochimica et Biophysica Acta 377: 410-420. 
Sauls, C. E., Nordlund, D. A. \& Lewis, W. J. (1979). Kairomones and their use for the management of entomophagous insects. VIII. Effects of diet on the kairomonal activity of frass from Heliothis zea (Boddie) larvae for Microplitis croceipes (Cresson). Journal of Chemical Ecology 5: 363-369.

Schmelz, E. A., Alborn, H. T. \& Tumlinson, J. H. (2001). The influence of intact-plant and excised-leaf bioassay designs on volicitin- and jasmonic acid-induced sesquiterpene volatile release in Zea mays. Planta 214: 171-179.

Schneider, P. (1972). Versuche zur frage der individuellen futterverteilung bei der kleinen roten waldameisen (Formica polyctena). Insectes Sociaux 19: 279-299.

Schüler, T. H., Poppy, G. M., Kerry, B. R. \& Denholm, I. (1999a). Potential side effects of insect-resistant transgenic plants on arthropod natural enemies. Trends in Biotechnology 17: 210-216.

Schüler, T. H., Potting, R. P. J., Denholm, I. \& Poppy, G. M. (1999b). Parasitoid behaviour and Bt plants. Nature 400: 825-826.

Schüler, G., Gorls, H. \& Boland, W. (2001). 6-Substituted indanoyl isoleucine conjugates mimic the biological activity of coronatine. European Journal of Organic Chemistry 1663-1668.

Schuster, M. F. \& Calderon, M. (1986). Interactions of host plant resistant genotypes and beneficial insects in cotton ecosystems. In Interactions of Plant Resistance and Parasitoids and Predators of Insects, eds. D. J. Boethel \& R. D. Eikenbary, pp. 84-97. New York: John Wiley \& Sons.

Schutz, S., Weissenbecker, B. \& Hummel, H. E. (1995). Impact of elevated atmospheric ozone on host plant finding of the Colorado beetle (Leptinotarsa decemlineata Say). Mededelingen van de Faculteit Landbouw Universiteit Gent 60: 819-824.

Scutareanu, P., Drukker, B., Bruin, J., Posthumus, M. A. \& Sabelis, M. W. (1997). Volatiles from Psylla-infested pear trees and their possible involvement in attraction of anthocorid predators. Journal of Chemical Ecology 23: 2241-2260.

Shah, D. M., Horsch, R. B., Klee, H. J. et al. (1986). Engineering herbicide tolerance in transgenic plants. Science 233: 478-481.

Shen, B., Zheng, Z. P. \& Dooner, H. K. (2000). A maize sesquiterpene cyclase gene induced by insect herbivory and volicitin. characterization of wild-type and mutant alleles. Proceedings of the National Academy of Sciences, USA 97: 14807-14812.

Shimoda, T., Takabayashi, J., Ashihara, W. \& Takafuji, A. (1997). Response of predatory insect Scolothrips takahashii toward herbivore-induced plant volatiles under laboratory and field conditions. Journal of Chemical Ecology 23: 2033-2048.

Shiojiri, K., Takabayashi, J., Yano, S. \& Takafuji, A. (2001). Infochemically mediated tritrophic interaction webs on cabbage plants. Population Ecology 43: 23-29.

(2002). Oviposition preferences of herbivores are affected by tritrophic interaction webs. Ecology Letters 5: 186-192.

Smith, L. L., Lanza, J. \& Smith, G. C. (1990). Amino-acid-concentrations in extrafloral nectar of Impatiens sultani increase after simulated herbivory. Ecology 71: 107-115.

Spiteller, D., Dettner, K. \& Boland, W. (2000). Gut bacteria may be involved in interactions between plants, herbivores and their predators: Microbial biosynthesis of $\mathrm{N}$-acylglutamine surfactants as elicitors of plant volatiles. Biological Chemistry 381: 755-762.

Stapel, J. O., Cortesero, A. M., Demoraes, C. M., Tumlinson, J. H. \& Lewis, W. J. (1997). Extrafloral nectar, honeydew, and sucrose effects on searching behavior and efficiency of Microplitis croceipes (Hymenoptera: Braconidae) in cotton. Environmental Entomology 26: 617-623. 
Steinberg, S., Dicke, M., Vet, L. E. M. \& Wanningen, R. (1992). Response of the braconid parasitoid Cotesia (= Apanteles) glomerata to volatile infochemicals: effects of bioassay set-up, parasitoid age and experience and barometric flux. Entomologia Experimentalis et Applicata 63: 163-175.

Steinberg, S., Dicke, M. \& Vet, L. E. M. (1993). Relative importance of infochemicals from 1st and 2nd trophic level in long-range host location by the larval parasitoid Cotesia glomerata. Journal of Chemical Ecology 19: 47-59.

Stephenson, A. G. (1982). The role of the extrafloral nectaries of Catalpa speciosa in limiting herbivory and increasing fruit production. Ecology 63: 663-669.

Stintzi, A., Weber, H., Reymond, P., Browse, J. \& Farmer, E. E. (2001). Plant defense in the absence of jasmonic acid: the role of cyclopentenones. Proceedings of the National Academy of Sciences, USA 98: 12837-12842.

Stout, M. J. \& Bostock, R. M. (1999). Specificity of induced responses to arthropods and pathogens. In Induced Defenses Against Pathogens and Herbivores, eds. A. A. Agrawal, S. Tuzun \& E. Bent, pp. 183-211. St Paul, MO: APS Press.

Sudd, J. H. \& Franks, N. R. (1987). The Behavioural Ecology of Ants. New York: Chapman \& Hall.

Sullivan, B. T., Pettersson, E. M., Seltmann, K. C. \& Berisford, C. W. (2000). Attraction of the bark beetle parasitoid Roptrocerus xylophagorum (Hymenoptera: Pteromalidae) to host-associated olfactory cues. Environmental Entomology 29: 1138-1151.

Swift, S. \& Lanza, J. (1993). How do Passiflora vines produce more extrafloral nectar after simulated herbivory? Bulletin of the Ecological Society of America 74: 451.

Takabayashi, J., Dicke, M. \& Posthumus, M. A. (1991a). Induction of indirect defense against spider-mites in uninfested lima-bean leaves. Phytochemistry 30: 1459-1462.

(1991b). Variation in composition of predator-attracting allelochemicals emitted by herbivore-infested plants: relative influence of plant and herbivore. Chemoecology 2: $1-6$.

(1994). Volatile herbivore-induced terpenoids in plant mite interactions: variation caused by biotic and abiotic factors. Journal of Chemical Ecology 20: 1329-1354.

Takabayashi, J., Takahashi, S., Dicke, M. \& Posthumus, M. A. (1995). Developmental stage of herbivore Pseudaletia separata affects production of herbivore-induced synomone by corn plants. Journal of Chemical Ecology 21: 273-287.

Takasu, K. \& Lewis, W. J. (1995). Importance of adult food sources to host searching of the larval parasitoid Microplitis croceipes. Biological Control 5: 25-30.

Tanowitz, B. D. \& Koehler, D. L. (1986). Carbohydrate analysis of floral and extra-floral nectars in selected taxa of Sansevieria (Agavaceae). Annals of Botany 58: $541-545$.

Taylor, J. S. (1932). Report on cotton insect and disease infestation. II. Notes on the American boll worm (Heliothis obselata F.) on cotton and its parasite (Microbracon brevicornis Wesm.). Scientific Bulletin of Research in Agriculture and Forestry of the Union of South Africa, vol. 113.

Tennant, L. E. \& Porter, S. D. (1991). Comparison of diets of 2 fire ant species (Hymenoptera, Formicidae): solid and liquid components. Journal of Entomological Science 26: 450-465.

Thaler, J. S. (1999). Jasmonate-inducible plant defences cause increased parasitism of herbivores. Nature 399: 686-688.

Thaler, J. S., Stout, M. J., Karban, R. \& Duffey, S. S. (1996). Exogenous jasmonates simulate insect wounding in tomato plants (Lycopersicon esculentum) in the laboratory and field. Journal of Chemical Ecology 22: 1767-1781. 
Thaler, J. S., Fidantsef, A. L., Duffey, S. S. \& Bostock, R. M. (1999). Trade-offs in plant defense against pathogens and herbivores: a field demonstration of chemical elicitors of induced resistance. Journal of Chemical Ecology 25: 1597-1609.

Thomson, N. J. (1981). Reversed animal-plant interactions: the evolution of insectivorous and ant-fed plants. Biological Journal of the Linnean Society 16: 147-155.

Tilman, D. (1978). Cherries, ants and tent caterpillars: timing of nectar production in relation to susceptibility of caterpillars to ant predation. Ecology 59: 686-692.

Tobin, J. E. (1994). Ants as primary consumers: diet and abundance in the Formicidae. In Nourishment and Evolution in Insect Societies, vol. 9, eds. J. H. Hunt \& C. A. Nalepa, pp. 279-307. Boulder, CO: Westview Press.

Treacy, M. F., Benedict, J. H., Segers, J. C., Morrison, R. K. \& Lopez, J. D. (1986). Role of cotton trichome density in bollworm (Lepidoptera, Noctuidae) egg parasitism. Environmental Entomology 15: 365-368.

Tscharntke, T., Thiessen, S., Dolch, R. \& Boland, W. (2001). Herbivory, induced resistance, and interplant signal transfer in Alnus glutinosa. Biochemical Systematics and Ecology 29: 1025-1047.

Tumlinson, J. H., Turlings, T. C. J. \& Lewis, W. J. (1992). The semiochemical complexes that mediate insect parasitoid foraging. Agricultural Zoological Review 5: 221-252.

Turlings, T. C. J. \& Benrey, B. (1998). Effects of plant metabolites on the behavior and development of parasitic wasps. Ecoscience 5: 321-333.

Turlings, T. C. J., Tumlinson, J. H. \& Lewis, W. J. (1990). Exploitation of herbivore-induced plant odors by host-seeking parasitic wasps. Science 250: 1251-1253.

Turlings, T. C. J., Tumlinson, J. H., Eller, F. J. \& Lewis, W. J. (1991a). Larval-damaged plants: source of volatile synomones that guide the parasitoid Cotesia marginiventris to the microhabitat of its hosts. Entomologia Experimentalis et Applicata 58: 75-82.

Turlings, T. C. J., Tumlinson, J. H., Heath, R. R., Proveaux, A. T. \& Doolittle, R. E. (1991b). Isolation and identification of allelochemicals that attract the larval parasitoid, Cotesia marginiventris (Cresson), to the microhabitat of one of its hosts. Journal of Chemical Ecology 17: 2235-2251.

Turlings, T. C. J., Mccall, P. J., Alborn, H. T. \& Tumlinson, J. H. (1993a). An elicitor in caterpillar oral secretions that induces corn seedlings to emit chemical signals attractive to parasitic wasps. Journal of Chemical Ecology 19: 411-425.

Turlings, T. C. J., Waeckers, F., Vet, L. E. M., Lewis, W. J. \& Tumlinson, J. H. (1993b). Learning of host-finding cues by hymenopterous parasitoids. In Insect Learning: Ecological and Evolutionary Perspectives, eds. D. R. Papaj \& A. Lewis, pp. 51-78. New York: Chapman \& Hall.

Turlings, T. C. J., Loughrin, J. H., Mccall, P. J., Rose, U. S. R., Lewis, W. J. \& Tumlinson, J. H. (1995). How caterpillar-damaged plants protect themselves by attracting parasitic wasps. Proceedings of the National Academy of Sciences, USA 92: 4169-4174.

Turlings, T. C. J., Lengwiler, U. B., Bernasconi, M. L. \& Wechsler, D. (1998). Timing of induced volatile emissions in maize seedlings. Planta 207: 146-152.

Turlings, T. C. J., Alborn, H. T., Loughrin, J. H. \& Tumlinson, J. H. (2000). Volicitin, an elicitor of maize volatiles in oral secretion of Spodoptera exigua: isolation and bioactivity. Journal of Chemical Ecology 26: 189-202.

Turlings, T. C. J., Gouinguené, S., Degen, T. \& Fritzsche Hoballah, M. E. (2002). The chemical ecology of plant-caterpillar-parasitoid interactions. In Multitrophic Level Interactions, eds. T. Tscharntke \& B. Hawkins, pp. 148-173. Cambridge: Cambridge University Press. 
Udayagiri, S. \& Jones, R. L. (1992a). Flight behavior of Macrocentrus grandii Goidanich (Hymenoptera, Braconidae), a specialist parasitoid of European corn borer (Lepidoptera, Pyralidae): factors influencing response to corn volatiles. Environmental Entomology 21: 1448-1456.

(1992b). Role of plant odor in parasitism of European corn borer by braconid specialist parasitoid Macrocentrus grandii Goidanich: isolation and characterization of plant synomones eliciting parasitoid flight response. Journal of Chemical Ecology 18: 1841-1855.

van der Meijden, E. \& Klinkhamer, P. G. L. (2000). Conflicting interests of plants and the natural enemies of herbivores. Oikos 89: 202-208.

van Loon, J. J. A., de Vos, E. W. \& Dicke, M. (2000a). Orientation behaviour of the predatory hemipteran Perillus bioculatus to plant and prey odours. Entomologia Experimentalis et Applicata 96: 51-58.

van Loon, J. J. A., de Boer, J. G. \& Dicke, M. (2000b). Parasitoid-plant mutualism: parasitoid attack of herbivore increases plant reproduction. Entomologia Experimentalis et Applicata 97: 219-227.

van Tol, R. W. H. M., van der Sommen, A. T. C., Boff, M. I. C., van Bezooijen, J., Sabelis, M. W. \& Smits, P. H. (2001). Plants protect their roots by alerting the enemies of grubs. Ecology Letters 4: 292-294.

Venzon, M., Janssen, A. \& Sabelis, M. W. (1999). Attraction of a generalist predator towards herbivore-infested plants. Entomologia Experimentalis et Applicata 93: 305-314.

Vet, L. E. M. \& Dicke, M. (1992). Ecology of infochemical use by natural enemies in a tritrophic context. Annual Review of Entomology 37: 141-172.

Vet, L. E. M., Wäckers, F. L. \& Dicke, M. (1991). How to hunt for hiding hosts: the reliability-detectability problem in foraging parasitoids. Netherlands Journal of Zoology 41: 202-213.

Vet, L. E. M., Lewis, W. J. \& Carde, R. T. (1995). Parasitoid foraging and learning. In Chemical Ecology of Insects 2, eds. R. T. Carde \& W. J. Bell, pp. 65-101. New York: Chapman \& Hall.

Vinson, S. B. (1968). Distribution of an oil carbohydrate and protein food source to members of imported fire ant colony. Journal of Economic Entomology 61: 712-714.

(1981). Habitat location. In Semiochemicals: Their Role in Pest Control, eds. D. A. Nordlund, W. J. Lewis \& R. L. Jones, pp. 51-77. New York: John Wiley \& Sons.

Vinson, S. B., Elzen, G. W. \& Williams, H. J. (1987). The influence of volatile plant allelochemicals on the third trophic level (parasitoids) and their herbivorous hosts. In Insect-Plants, eds. V. Labeyerie, G. Fabres \& D. Lachaise, pp. 109-114. Dordrecht: Junk.

Wäckers, F. L. (1994). The effect of food-deprivation on the innate visual and olfactory preferences in the parasitoid Cotesia rubecula. Journal of Insect Physiology 40: 641-649.

Wäckers, F. L. \& Wunderlin, R. (1999). Induction of cotton extrafloral nectar production in response to herbivory does not require a herbivore-specific elicitor. Entomologia Experimentalis et Applicata 91: 149-154.

Wäckers, F. L., Zuber, D., Wunderlin, R. \& Keller, F. (2001). The effect of herbivory on temporal and spatial dynamics of foliar nectar production in cotton and castor. Annals of Botany 87: 365-370.

Wadhams, L. J., Birkett, M. A., Powell, W. \& Woodcock, C. M. (1999). Aphids, predators, and parasitoids. In Insect-Plant Interactions and Induced Plant Defences, eds. D. J. Chadwick \& J. A. Goode, pp. 60-67. London: John Wiley \& Sons. 
Wagner, D. (1997). The influence of ant nests on Acacia seed production, herbivory and soil nutrients. Journal of Ecology 85: 83-93.

Walling, L. L. (2000). The myriad plant responses to herbivores. Journal of Plant Growth Regulation 19: 195-216.

Wegener, R., Schulz, S., Meiners, T., Hadwich, K. \& Hilker, M. (2001). Analysis of volatiles induced by oviposition of elm leaf beetle Xanthogaleruca luteola on Ulmus minor. Journal of Chemical Ecology 27: 499-515.

Weiler, E. W., Kutchan, T. M., Gorba, T., Brodschelm, W., Niesel, U. \& Bublitz, F. (1994). The Pseudomonas phytotoxin coronatine mimics octadecanoid signaling molecules of higher-plants. Febs Letters 345: 9-13.

Weissbecker, B., van Loon, J. J. A., Posthumus, M. A., Bouwmeester, H. J. \& Dicke, M. (2000). Identification of volatile potato sesquiterpenoids and their olfactory detection by the two-spotted stinkbug Perillus bioculatus. Journal of Chemical Ecology 26: 1433-1445.

Wertz, P. \& Downing, D. (1989). Beta-glucosidase activity in porcine epidermis. Biochimica et Biophysica Acta 978: 115.

Whitman, D. W. (1988). Allelochemical interactions among plants, herbivores, and their predators. In Novel Aspects of Insect-Plant Interactions, eds. P. Barbosa \& D. Letourneau, pp. 207-248. New York: John Wiley \& Sons.

(1994). Plant bodyguards: mutualistic interactions between plants and the third trophic level. In Functional Dynamics of Phytophagous Insects, ed. T. N. Ananthakrishan, pp. 207-248. New Dehli: Oxford and IBH Publishing.

Winz, R. A. \& Baldwin, I. T. (2001). Molecular interactions between the specialist herbivore Manduca sexta (Lepidoptera, Sphingidae) and its natural host Nicotiana attenuata. IV. Insect-induced ethylene reduces jasmonate-induced nicotine accumulation by regulating putrescine $N$-methyltransferase transcripts. Plant Physiology 125: 2189-2202.

$\mathrm{Xu}$, N. \& Chen, Z. (1999). Isolation and identification of tea plant volatiles attractive to tea geometrid parasitoids. Acta Entomologica Sinica 42: 126-131.

$\mathrm{Yu}, \mathrm{S}$. (1989). Beta-glucosidase in four phytophagous Lepidoptera. Insect Biochemistry 19: 103 .

Zangerl, A. R. \& Bazzaz, F. A. (1992). Theory and pattern in plant defense allocation. In Plant Resistance to Herbivores and Pathogens, eds. R. Fritz \& E. L. Simms, pp. 363-392. Chicago, UL: University of Chicago Press.

Zangerl, A. R. \& Rutledge, C. E. (1996). The probability of attack and patterns of constitutive and induced defense: a test of optimal defense theory. American Naturalist 147: 599-608.

Zimmermann, M. (1932). Ueber die extra-floralen Nectarien der Angiospermen. Botanisches Zentralblatt 49: 99-196.

Zwölfer, H. \& Kraus, M. (1957). Biocoenotic studies on the parasites of two fir and two oak tortricids. Entomophaga 2: 173-196. 